University of San Diego

Digital USD

1990-11-01

\title{
The Essential Characteristics of Advocacy Associated with the Nurse-Client Relationship: The Client's Perspective
}

Victoria Louise Cole Schonlau DNSc, MPA, BSN, RN

University of San Diego

Follow this and additional works at: https://digital.sandiego.edu/dissertations

Part of the Nursing Commons

\section{Digital USD Citation}

Cole Schonlau, Victoria Louise DNSc, MPA, BSN, RN, "The Essential Characteristics of Advocacy Associated with the Nurse-Client Relationship: The Client's Perspective" (1990). Dissertations. 227. https://digital.sandiego.edu/dissertations/227

This Dissertation: Open Access is brought to you for free and open access by the Theses and Dissertations at Digital USD. It has been accepted for inclusion in Dissertations by an authorized administrator of Digital USD. For more information, please contact digital@sandiego.edu. 
THE ESSENTIAL CHARACTERISTICS OF ADVOCACY ASSOCIATED WITH THE NURSE-CLIENT RELATIONSHIP:

THE CLIENT'S PERSPECTIVE

\author{
by \\ Victoria Louise Cole Schonlau, B.S.N., M.P.A., R.N. \\ A dissertation presented to the \\ FACULTY OF THE PHILIP Y. HAHN SCHOOL OF NURSING \\ UNIVERSITY OF SAN DIEGO \\ In partial fulfillment of the \\ requirements for the degree \\ DOCTOR OF NURSING SCIENCE
}

November 1990 


\begin{abstract}
THE ESSENTIAL CHARACTERISTICS OF ADVOCACY ASSOCIATED WITH THE NURSE-CLIENT RELATIONSHIP: THE CLIENT'S PERSPECTIVE
\end{abstract}

The purpose of this phenomenological study was to describe clients' lived experiences of advocacy associated with the nurse-client relationship. The sample consisted of ten non-hospitalized adults, 19 to 72 years of age, who had a hospitalization or ambulatory relationship with a registered nurse within the previous six months. Data were gathered via interviews initiated with the same open-ended question. Georgi's five step method was used for data analysis.

Four essential characteristics of advocacy associated with the nurse-client relationship were identified. Described by clients as nurse attributes, behaviors, and actions, they were labelled: Competent Knower, Competent Doer, Humanizer, and Communicator. Clients perceived the Competent knower to be knowledgeable about client conditions and needs, experienced in nursing practice, and capable. The Competent Doer acted on behalf of clients, either by own initiative or at clients' requests, solved problems, served as intermediary, followed through on the clients' needs and desires, demonstrated competence in technical and supportive skills, and exhibited leadership, including taking responsibility for care given by others under supervision. 
In relationships with client, family, and professional colleagues, the Humanizer was perceived as a personable, caring team member/leader who intervened on clients' behalf, supported their decisions, treated them as valued individuals, encouraged clients, went the extra mile and made self available to clients by being there in presence. The Communicator transmitted and exchanged information with client, family, physician, and other health care professionals, served as liaison between them, provided explanations and education, and kept clients informed by disclosing pertinent information voluntarily and by request. clients perceived that advocacy was not demonstrated by all nurses and was integrated with other roles within the whole of the nurse-client relationship. Comparisons are made between clients' positive experiences (nurses demonstrated characteristics of advocacy) and negative experiences (which lacked advocacy), and between clients' and nurses' perspectives of advocacy. Implications and research recommendations for clinical practice, education, and administration are addressed, including the development of further validation studies to determine generalizability, and dissemination of the new description to other nurses and disciplines. 
C NOVEMBER, 1990 VICTORIA LOUISE COLE SCHONLAU ALL RIGHTS RESERVED 


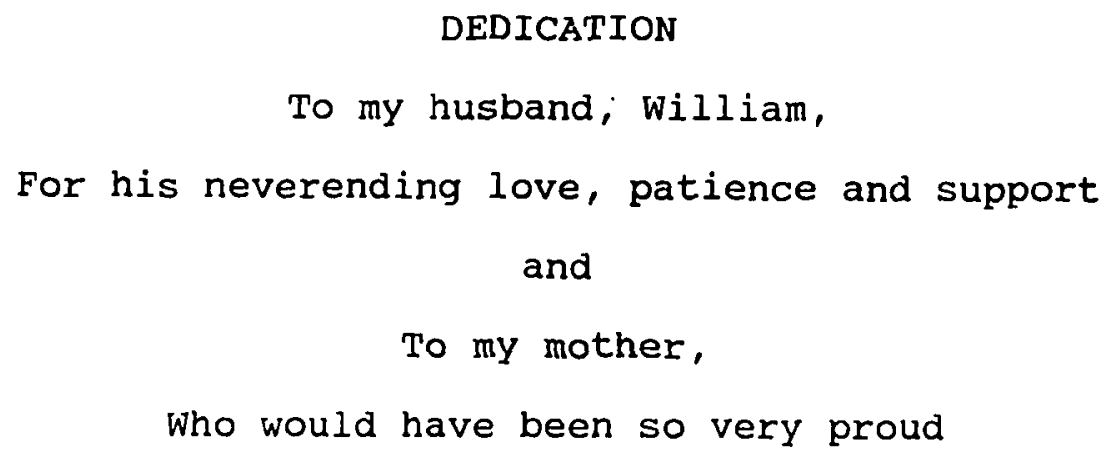




\section{ACKNOWLEDGEMENTS}

Sincere gratiiude is extended to my dissertation committee: to Dr. Janet K. Harrison, my chairperson, whose support and encouragement were always evident. Her clear thinking and critique of my work are truly appreciated. To Dr. Rita Snyder-Halpern whose insightful comments and questions were very helpful in the development of this study. I wish to give special acknowledgement to my methodologist, Dr. Anna K. Omery, who became my mentor and friend during this research process. I am very appreciative of the innumerable hours of counsel, critique, and encouragement she gave so willingly during the many months of data collection, analysis, and writing of this report. I always left her office feeling charged with energy and reaffirmed that I was doing a good job, that this was a sound, rigorous, quality phenomenological study.

I am deeply grateful to family, friends, and colleagues for their support during my doctoral studies and completion of this dissertation. Due to my frequent and sometimes lengthy stays at school, my sister, Patricia c. Wolfe, received little support from me in making difficult decisions and arrangements for the care of our mother with Alzheimer's disease. Pat always understood and tried to allay my guilt feelings of abandoning her to be the sole advocate. Although many miles separate us, fellow doctoral students provided support and encouragement during the conceptualization and completion of this research. I am 
very thankful to Dr. Christine Latham, Dr. Judith Dempster, and Dr. Donna Adams for their $31 / 2$ years of friendship and comradery. In addition, the collegial support and encouragement of Bonnie Siegal and Elaine Goehner during my doctoral studies were very much appreciated.

The contribution of Dr. Irene S. Palmer, Dean Emeritus, to my intellectual development is especially acknowledged. Her pearls of wisdom and vast knowledge of the history of nursing evoked in me an unquenchable thirst for seeking and discovering new knowledge.

I would like to extend a special thank you to ketty Neimann, secretary at the: school of nursing. Ketty always availed herself to help us surmount system problems, especially those of us from out of town. She really cared for and about us. I would also like to acknowledge the help of the librarians at the University of San Diego Copley Library. Marjo Gray, Devon Milner, and Janet Murphy's dedication to helping doctoral nursing students invokes indebtedness.

Finally, besides his love and support during my doctoral studies, William's computer work on the illustrations contributed to the final appearance of this document and make him a permanent, integrated part of this work. 
Abstract.

Dedication

Acknowledgements........................ ii

List of Tables.......................... $x$

List of Illustrations.................... xi

List of Appendices....................... xii

CHAPTER ONE

INTRODUCTION.......................... 1

Introduction to the Problem................ 1

Statement of the Problem................. 3

Research Questions...................... 4

Definition of the Terms................. 4

Assumptions.......................... 5

Significance of the study................ 6

CHAPTER TWO

REVIEW OF THE LITERATURE.................. 8

Advocacy: Professional Perspectives........... 8

Law.............................. 9

Social work.................. 10

Medicine....................... 12

Advocacy and the Nurse-client Relationship:

Nursing's Perspective.................... 14

Theoretical Foundation................ 15

Nursing Models of the Nurse-client

Relationship...................... 18 
Ethical Principles, Moral Rules and

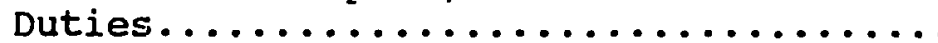

Murphy's Nurse-patient Relationship

Models.......................

Gadow's Models of the Nurse-patient

Relationship................... 22

Smith's Nurse-patient Relationship Models....................... 24

Kohnke's Advocacy Model............ 25

A Comparison of the Nurse-client

Relationship Models.............. 26

Empirical Background................ 30

Nurses' and Clients' Perceptions of the Nurse-

client Relationship: Empirical Comparisons........

Advocacy and the Nurse-client Relationship:

The Client's Perspective................ 36

Client Participation in Health Care

Decision Making................... 36

Client Satisfaction with Nursing Care

Behaviors in the Nurse-client Relationship... 40

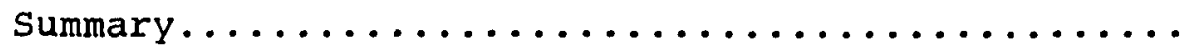

CHAPTER THREE

METHODOLOGY............................ 44

Phenomenology as an Appropriate Method......... 44

Research Design...................... 45

Study Participants..................... 46

Data Collection....................... 49

Validity and verifiability of Data........... 52

Data Analysis Procedure.................. 53

vi

Reproduced with permission of the copyright owner. Further reproduction prohibited without permission. 
CHAPTER FOUR

REPORT OF THE FINDINGS.................... 58

Study Participants..................... 58

Description of the Essential Characteristics of Advocacy Associated with the Nurse-client

Relationship from the Client's Perspective....... 59

Essential Characteristic: Competent Knower... 61

Knowledgeable.................. 62

Experienced.................. 63

Capable......................... 64

Essential Characteristic: Competent Doer..... 65

Competent in Technical and Supportive

skills..................... 66

Took Action as Problem-solver and

Intermediary.................. 67

Followed Through on Client's Needs

and Desires...................... 68

Displayed Leadership/supervisory Skills. 69

Essential Characteristic: Humanizer........ 70

Caring..................... 71

Valued Client as Individual Person..... 72

Went the Extra Mile, Made Extra Efforts. 73

Presencing.................... 74

Relating.................... 74

Intervened on Client's Behalf/supported

Client's Decision................. 76

Coaching................... 77

Essential Characteristic: Communicator...... 79

Communication iliaison............. 79

Explanation/education............ 81

vii

Reproduced with permission of the copyright owner. Further reproduction prohibited without permission. 
Page

Information Giving.............. 82

The Essential Characteristics of Advocacy Associated with the Nurse-client

Relationship: Summary................ 84

The Relationships Between the Essential

Characteristics........................ 85

Additional Findings.................... 88

Negative Experiences: Description of

Nurses who Lacked Advocacy............. 88

Incompetent in knowledge and

Performance/actions.............. 88

Dehumanizing.................... 96

Client Reports of Self-sufficiency,

Self-reliance, Self-care.............. 102

CHAPTER FIVE

DISCUSSION OF THE FINDINGS................... 104

Assumptions Reviewed....................... 104

Nurse-client Relationship Models and

the Client's Perspective................. 108

Client Perceptions and Murphy's Models...... 109

Client Perceptions and Gadow's Models

of Paternalism and Existential Advocacy...... 110

Client Perceptions and Kohnke's

Advocacy Model and Gadow's Consumerism/

Patient Rights Model................. 113

Client Perceptions and Smith's Models....... 114

Negative Experiences and Positive Experiences:

A Comparison........................... 115

Advocacy as an Integrated Role within the

Nurse-client Relationship................ 118

viii

Reproduced with permission of the copyright owner. Further reproduction prohibited without permission. 
CHAPTER SIX

IMPLICATIONS AND SUMMARY .................. 121

Implications and Research Recommendations....... 121

Clinical Practice.................. 121

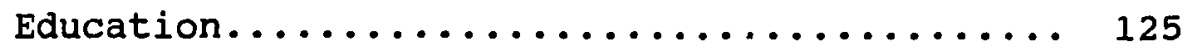

Administration.................... 127

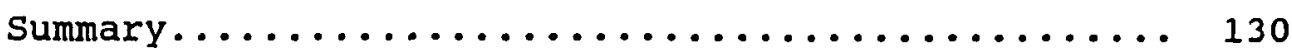

REFERENCES............................ 133

ix

Reproduced with permission of the copyright owner. Further reproduction prohibited without permission. 
Page

Table 1. Demographic Data of Stuäy Farticipants...... 59

Table 2. Essential Characteristic: Competent Knower Minor Characteristics................. 62

Table 3. Essential Characteristic: Competent Doer Minor Characteristics................. 66

Table 4. Essential Characteristic: Humanizer -

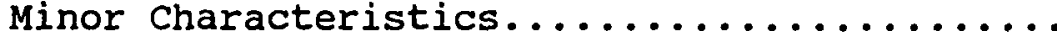

Table 5. Essential Characteristic: Communicator Minor Characteristics.................

Table 6. Not Competent in Knowledge and Performance/ actions: Characteristics Converse to

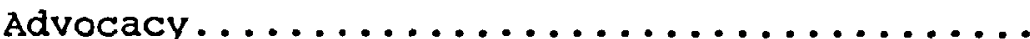

Table 7. Dehumanizing: Characteristics Converse to Advocacy........................... 
Figure 1. Affiliations Between the Models of the Nurse-client Relationship........... 27

Figure 2. Relationships Between the Essential Major Characteristics................ 86 
Appendix A. Letter to Community Health Care

Professionals Regarding Study and

Request for Referral of potential

Participants.................... 148

Appendix B. Consent to Participate.............. 151

Appendix c. Human Subjects Review Committee

Approval....................... 153

xii

Reproduced with permission of the copyright owner. Further reproduction prohibited without permission. 
CHAPTER ONE

INTRODUCTION

The profession of nursing has a social mandate to meet society's needs and does so by diagnosing and treating human responses to actual or potential health problems of clients (American Nurses' Association, 1980). Nurses provide diagnostic and therapeutic interventions and care within the context of the nurse-client relationship, the nature of which is determined by the client's unique human needs and the nurse's response to them (Curtin, 1982). In many situations the client's family is also a recipient of nursing care and a participant in the nurse-client relationship (Barrow, 1988); indeed, the nurse's relationship with the family may, in some circumstances, be more significant than the nurse's relationship with the client (e.g., parents of children, families of incompetent elderly or terminally ill).

The interpersonal relationship between nurse and client has numerous facets, and for many nurses client advocacy is an integral part of the nurse-client relationship. Advocacy is more than just campaigning for clients because of the professional commitment and relationship; it has been espoused to be human advocacy and the philosophical foundation and ideal of nursing. In human advocacy each 
person is an interrelated and interdependent unity with the human rights of freedom, respect and integrity (Curtin, 1979).

Nurses describe client advocacy in the nurse-client relationship as the acceptance of the client as a unique human being (Murphy, 1983), the act of loving and caring for others as one would for oneself (Kohnke, 1980), and a partnership between nurse and client (Gadow, 1980). Client advocacy has been said to entail the nurse's participation with the client as a means of enhancing client autonomy by clarifying information, examining available alternatives of action and assisting clients in illuminating personal beliefs, values and goals (Gadow, 1980); helping the client decide (Corcoran, 1988); supporting the client's decision, even when the nurse believes that the decision is not in the client's best interest (Kohnke, 1982); and facilitating the client's efforts to obtain needed care by intervening on behalf of the client with the physician or institution (Murphy, 1979).

Winslow (1984), surveying the nursing literature on advocacy, found that nurses define client advocacy in many ways. It was described as doing what is best for the client, helping the client to obtain needed health care, assuring quality care, serving as liaison between the client and the health care system, defending the client's rights, 
assuring the client's self-determination, and assisting the client to deal with fear.

Because the nurse-client relationship is central to nursing practice, the elements of that relationship ascribed to by nurses concern nursing vitally and are thus worthy of investigation. Nevertheless, nurses' descriptions of advocacy have been theoretical and not the result of empirical investigation. Equally important, it was unknown if clients view advocacy in a similar way to nurses because of the paucity of literature that describes client advocacy associated with the nurse-client relationship from the client's perspective. The purpose of this study was to describe the client's lived experience of advocacy associated with the nurse-client relationship. Verbal descriptions of client experiences with the nurse-client relationship and the aspect of advocacy were obtained from a group of volunteer participants who had had a professional relationship with a registered nurse within the past six months. The client's perspective of the essential characteristics of advocacy associated with the nurse-client relationship were extracted from the descriptions by phenomenological analysis.

Statement of the Problem

Nursing has postulated that advocacy is an important aspect of the nurse-client relationship; however, no investigation had been conducted regarding the client's 
perspective of advocacy as an important aspect of the nurseclient relationship.

\section{Research Questions}

The general research questions guiding the investigation were:

1. What are the essential characteristics of advocacy associated with the nurse-client relationship as described from the client's experiential perspective?

2. What is the relationship between the essential characteristics of advocacy in the nurse-client relationship?

$$
\text { Definition of the Terms }
$$

The terms described here (client, nurse-client relationship, and advocacy) were the conceptual orientations that framed the investigation. For purposes of this study these terms were defined as follows:

A client is a person who engages the professional advice or services of another and may be under the protection of the professional (Webster, 1986). A client may therefore be either the direct recipient of the professional service or a significant other who engages the professional's services on behalf of another.

Patient implies a more dependent and passive position in the nurse-client relationship, referring to an individual awaiting, or under, medical care and treatment or one that is acted upon (Webster, 1986). Client thus connotes a more 
interdependent, active participation in the relationship and encompasses relationships between clients and nurses in all health care and health promotion settings. The term "patient" is considered subsumed under the broader term "client."

Nurse-Client Relationship was defined as the therapeutic interaction between an individual who is licensed to provide nursing care and the recipient or recipient's significant others during the time period that the recipient is being provided service. Nursing services occur in all settings in which a registered nurse provides care or promotes health.

Advocacy is a philosophical and ethical orientation that can be identified by certain behaviors. Such behaviors include treating the individual as a human being with respect and dignity, defending an individual's rights, interceding on someone's behalf, informing an individual of alternatives, disclosing pertinent information, helping the individual make a decision, and supporting the individual's choices and desires.

Assumptions

Eidetic phenomenological analysis requires that investigators state their assumptions regarding the phenomenon to be studied and then "bracket" or "suspend" them in order to fully understand the experiences of the subject and not impose any preconceived hypothesis on the 
experience. The following assumptions that were made regarding this investigation will be compared with the results of the proposed study following data analysis:

1. Advocacy is an integral part of the nurse-client relationship.

2. Nursing considers advocacy a vital role for the professional nurse. Nurses assume the role of client advocate as part of their professional socialization.

3. Nurses advocate for human dignity and client rights to autonomy and for client participation in health care decision making.

4. The nurse may advocate for the client without the client's knowledge.

5. Clients do not differentiate between advocacy and caring in the nurse-client relationship. Their descriptions of nurse-client relationships that were caring include advocacy behaviors (Reimen, 1986; E. Smith, 1987).

Significance of the study

In this era, increased specialization and righ

technology that focuses perhaps more on cure than care (Flaskerund, Halloran, Janken, Lund, \& Zetterland, 1979; Winslow, 1984) can result in fragmentation, depersonalization, and dehumanization of health care and nursing care delivery (Lanara, 1976). Nurses can facilitate a change in this focus by fostering holistic, humanizing, and caring interactions through the nurse-client 
relationship, interactions that clients perceive as meaningful and satisfying. The first step toward achieving this focus is understanding clients' desires and expectations of the nurse-client relationship.

Do clients want nurses to be their advocates? Winslow (1984), for example, postulated that patients and families are often unprepared to accept the nurse as an advocate. What nursing behaviors do clients expect and find desirable in the nurse-client relationship? What do clients want from nurses? During this study, as clients described their experiences with nurses, they reported a variety of desirable and undesirable nursing care behaviors, attributes and actions. While the focus of this study was the characteristics of advocacy demonstrated by the nurse, the depth of the descriptions enhanced insight into the client's perspective of the nurse-client relationship and increased the knowledge needed to strengthen the relationship between nurse and client, thereby contributing to client satisfaction with the nursing care delivery system. 
CHAPTER TWO

REVIEW OF THE LITERATURE

This chapter examines the literature related to advocacy; specifically, how the professions of law, social work and medicine view advocacy and how both nurses and clients perceive advocacy and the nurse-client relationship. Theoretical literature that was examined is presented because it provides the framework for nursing's perspective of client advocacy, which includes the major nursing models of the nurse-client relationship, and augments scanty empirical investigation related to advocacy. The client's perspective of advocacy was found in related literature dealing with participation in health care decision making and client satisfaction with nursing care behaviors. The scarcity of literature related directly to the client's perspective of advocacy associated with the nurse-client relationship established the necessity for this phenomenological investigation.

Advocacy: Professional Perspectives

The professions of law, social work and medicine describe the importance of client advocacy. From an empirical stance, however, the phenomenon of client advocacy is vastly unexplored. 
Law

The profession of law is directly referenced in the dictionary examination of the origins and common usages of advocacy. Derived from the 14th century French word advocacie, advocacy is the function of an advocate who is called upon to perform the work of advocating, to plead for, to defend or speak for (Oxford English Dictionary, 1933). Advocacy in the profession of law is rooted in this primary definition. An advocate is one who makes it his or her profession to conduct the trial of causes before judicial tribunals (Dictionary of Philosophy and Psychology, 1960). Legal advocate is the first and most common definition of advocate (Oxford English Dictionary, 1933).

Rubenstein (1986) theoretically postulated that legal advocacy has played an important role in the cuality of health care. He described legal advocacy as lawsuits that have increased the availability of decent care to patients, helped to supply funds, and ensured accountability for care.

Review of the literature related to research on advocacy by the legal profession revealed that attorneys rarely describe traditional empirical research. Rather, case reviews and the development of a particular topic or concept were listed as research. Examples of legal research on advocacy include: the symbols and meanings of advocacy in the emergence of mental health advocacy as political reform (Milner, 1986), development of human rights and humanitarian 
law (Schindler, 1982), and a study of human rights in international law (Sucharitkul, 1987).

In the only empirical study discovered, Landon (1985) examined the impact of small town country law practice on the professional responsibility of advocacy. His exploratory study suggested that in a small town expectations of clients, community, and colleagues, rather than the content of law school socialization, influence the definition of advocacy and shape the context of the attorney's practice.

There is little literature in the law profession and only one empirical study that referred to advocacy. Attorneys are defined as legal advocates; unlike other professions, advocacy is their primary function. The advocacy role taken by social workers and espoused by physicians and nurses is the second common definition of advocate--one who pleads, defends, intercedes or speaks for, or in behalf of, another (Oxford English Dictionary, 1933). This will be explored in the ensuing sections.

\section{Social Work}

Social workers describe client advocacy as an important aspect of their profession; however, empirical investigation into this role is minimal. Advocacy is not defined in the social work literature. Rather, it is described as advocacy activities that include mediating between the interests of society and the interests of the individual in the public 
defender's office (Ashford, Macht, \& Mylym, 1987). Likewise, enabling clients to develop their own internal and external resources, take their own actions, and become their own change agents (Pearlman \& Edwards, 1982) is described as advocacy. Social workers also use advocacy in discharge planning and ensuring that government programs are accessible and appropriate for eligible patients and families (Lurie, 1982).

Bendor (1987) asserted that, for effective practice, the hospital based social worker must place a strong emphasis on client-centered advocacy while still supporting the institution. Nevertheless, although advocacy has been traditionally viewed as an important role for social workers, in practice they rarely have the time, resources, or institutional support to fully exercise an advocacy role (Blazyk, Crawford, \& wimberley, 1987).

The above theoretical premises are supported by only two investigations that relate to the social worker's role as advocate. Willets (1980) conducted informal interviews with a small sample of social work advocates. He found that lack of resources resulted in an inability to utilize the role of advocate to its maximum potential and led to frustration and decreased job satisfaction. There was reference to one advocate who espoused that social workers should exercise their advocacy role by educating clients to self-advocacy, thereby increasing client independence. 
In an exploratory-descriptive study on the utilization of advocacy and attitudes of advocates towards advocacy, Epstein (1981) conducted interviews with 105 social work advocates in which he found that personal experiences motivated the advocates to advocacy roles. Epstein found that there were internal and external obstacles to the advocate and that success, stress and burnout were included as outcomes to advocacy; job satisfaction related to success and dissatisfaction to obstacles. He also found subjects promoting client self-advocacy.

Client advocacy activities of social workers have been examined; although important to their practice, research has been minimal. Rewards, frustrations with the role, and obstacles to its implementation have been described. Physicians also espouse patient/client advocacy. Literature related to client advocacy and medicine is presented in the following section.

\section{Medicine}

Physicians posit that they are client advocates when acting on behalf of what they believe to be the client's best interests. They have conducted minimal research in the area of patient/client advocacy; any literature is in the form of editorials, short commentaries, and reports of addresses to professional society meetings. Physicians speculate that paternalism is out of favor and that the imperative of patient autonomy echoes the past abuses of 
paternalism (Miles, 1988), making patient advocacy an important professional responsibility for the physician (Klocke, 1988). Ás a result, physicians need to be dedicated to securing necessary and appropriate care for patients and families, while avoiding cost ineffective tests and treatments of questionable value (Lindes, 1988). Physicians also postulate that patient advocacy offers only the highest quality medical care by demonstrating intolerance for mediocrity through peer review and censure of incompetent practice, by exerting intense efforts to eradicate threats to public health, and by treating all patients with courtesy and respect (Hotchkiss, 1987). Fraser (1987) suggests that long term care ombudsmen and physicians have similar advocacy goals of protecting the basic rights of residents, including their rights to freedom from abuse, to dignity, to privacy and confidentiality in treatment, to self-determination and other basic civil liberties (Fraser, 1987).

One investigation, related to physician or medical student advocacy issues, focused on informed consent. Cohen, McCullough, Kessel, Apostolides, Heiderich and Alden (1988) surveyed a national sample of 1596 graduating medical students. They used a questionnaire designed to describe behavior relative to student interaction with patients, to quantify students' perceptions of obtaining informed consent for their involvement in the care of patients, and to 
ascertain the students' personal perspectives on the rights of patients in teaching hospitals. Findings indicated that medical students do not consistently obtain consent nor do they always identify themselves as unicensed physicians. Consequently, information relevant to patients' decisions about medical care is not disclosed to patierits because meáical students do not act in a manner consistert with that fundamental requirement of informed consent. The investigators also found that medical students were in general agreement that patients should not have the right to reject student participation in general care but should be allowed to refuse student participation in some unspecified aspects of care rendered.

Physicians espouse the importance of client advocacy as described in this review. There is, however, minimal empirical literature related to client advocacy. Advocacy and the Nurse-client Relationship: Nursing's Perspective

Nurses hold strong beliefs that client advocacy is an important aspect of the nurse-client relationship. It is important that nursing empirically study client advocacy associated with the nurse-client relationship from the client's perspective because most of the literature supporting this role for nurses has been theoretical and the minimal research done has been from the perspective of the nurse. A review of nursing's theoretical perspective of 
advocacy and the nurse-client relationship and empirical literature provide significance for this study. Theoretical Foundation

Client advocacy is said to be integral to the nurseclient relationship. Nursing has had many images that influence the role of the nurse and the relationships between clients and nurses. Historically, the nurse has been viewed as a surrogate mother caring for the patient, the patient's family, and other health care professionals as a mother cares for her own family (Aroskar, 1980; Flaherty, 1982; Winslow, 1984); as a healer and technician through a medical surrogate role (Murphy, 1979; Yarling \& MCElmurry, 1986); and as a health educator (Davis \& Jameton, 1987). The term patient/client advocate (Gadow, 1979; Kohnke, 1980; Murphy, 1983) has surfaced to describe an important role dimension in nurse-client relationships.

Literature has dealt with client advocacy as a role for nursing more frequently since the early 1970's. Christy (1973) saw client advocacy as the role of the true professional nurse who possesses and blends the three attributes of advocacy--motivation, skill, and knowledge. Advocacy is not a new role for nuxses. Early nurse leaders including Nightingale, Barton, Wald, and Dock, were committed to advocacy of human dignity and rights, humanitarianism, and accountability of the nurse to the 
patient (Christy, 1973; Donahue, 1978; Sundeen, Stuart, Rankin, \& Cohen, 1989).

Fay (1978) asserted that advocacy includes: helping the patient make his needs known to the physician or other health care professionals; seeking out additional services and requesting referrals when appropriate; and requesting improvements in patient service, such as specific patient equipment. Fay promoted advocacy as an essential part of nursing and believed that it should be explicitly stated in the definition of nursing practice.

Some state professional licensing criteria (e.g., California Board of Registered Nurses, 1985) and professional organizations (e.g., American Nurses' Association, 1985a) support Fay's (1978) position on nurses as patient advocates. Changes in the American Nurses Association "Code for Nurses" between 1950 and 1976 indicate a shift in loyalty and accountability from the physician to the patient (Flaherty, 1982; Nelson, 1988), and the relationship of the nurse to patient self-determination is termed "advocacy" in the 1985 ANA Code for Nurses (American Nurses' Association, 1985a).

Nurses list "client advocate" among their many roles and espouse responsibility to enforce client rights (Walsh, 1978). Kosik (1972) believes that nurses need a deeper commitment to client advocacy than merely supporting the advocacy of universal human rights. The nurse's role should 
be to support patient autonomy by insuring adequate information and understanding to increase patients' knowledge regarding their rights, expectations, and bureaucratic systems (Kosik, 1972; National League for Nursing, 1978; Payton, 1979).

The social revolution of consumer action and the patient's right to know and participate in decision making have been discussed at length in the literature (Annas \& Healey, 1974; Aydelotte, 1978; Kelly, 1976; Novello, 1978; Sparrow, 1978; Walsh, 1978). Quinn and Somers (1974) asserted that this movement is positive because nurses assume responsibility and accountability for their actions by placing care to the client first over service to the institution.

Sundeen et al. (1989) theorize the interpersonal relationship between nurse and client to be a helping and supportive relationship. King (1971) described the nurseclient relationship as two individuals interacting through a learning experience; facing, sharing and, if possible, resolving a health problem; and discovering ways to adapt to the situation.

The nurse-client relationship is also described as a covenantal relationship grounded in the moral principle of fidelity and characterized by mutuality, reciprocity, and responsiveness on the part of both the client and nurse (Cooper, 1988; Lumpp, 1979). Sundeen et al. (1989) also 
stated that autonomy and mutuality are closely related and essential in the development of the nurse-client relationship. They described autonomy as concerned with the ability to be self-directed and mutuality as involving the process of sharing with another person. They also indicated that the nurse's advocacy role promotes client autonomy and fosters mutual responsibility in the relationship.

Theoretical underpinnings of advocacy and the nurseclient relationship have been reviewed from a variety of nursing perspectives. These perspectives provide a basis for the presentation of the major nursing models of the nurse-client relationship.

\section{Nursing Models of the Nurse-Client Relationship}

Murphy, Gadow, Smith, and Kohnke proposed nursepatient/client relationships with advocacy as the most ideal component. These models are based on moral rules, duties and the ethical principles of autonomy, beneficence, and nonmaleficence. An examination of these ethical principles, the proposed nurse-client relationship models, and their similarities and contrasts contribute to the understanding of the nurse's perspective of advocacy associated with the nurse-client relationship. Ethical Principles, Moral Rules and Duties Autonomy. Autonomy is defined as the right to selfdetermination without constraints by others (Beauchamp \& Childress, 1983). Constraints include coercion, deception, 
lying, failure to supply necessary information, and narrowing the range of alternatives (Mappes \& zembaty, 1986).

Thompson (1982) described morals as the "shoulds and oughts" of life and ethics the reasons, the "whys" behind the morals. The rules of confidentiality and privacy and the moral duties of veracity (to tell the truth, not to lie and not to deceive others) and fidelity (faithfulness), which includes respect for others, promise-keeping, and trust, are explicated from the principle of autonomy (Beauchamp \& Childress, 1983).

Advocates respect human dignity and the rights of the individual (Donahue, 1978) inherent in the principle of autonomy. They find themselves in ethical conflicts, however, when the individual's capability for rational decision making toward appropriate ends and ability to realize goals is limited by internal constraints (Mappes \& Zembaty, 1986). Such internal contraints include diminished physical or mental capacities as found in incompetent elders, quadraplegics, children, or the comatose. When capabilities are compromised and autonomy limited, other ethical principles become more prominent to the advocate. Beneficence and Nonmaleficence. Beneficence (the duty to do good) and nonmaleficence ("do no harm") are on a continuum (Thompson \& Thompson, 1985). Beneficence requires positive action to assist others in attaining their 
legitimate and important interests. Both beneficence and nonmaleficence do this through the prevention and removal of harm and the balancing of benefits and harm (burden/riskbenefit analysis) (Beauchamp \& Childress, 1983). Conflicts arise for advocates when autonomy is limited. Beneficence and nonmaleficence become more dominant because professionals are socialized to acting in the individual's best interest (Gadow, 1983). The nurse-client relationship models of Murphy, Gadow, Smith, and Kohnke reflect the ethical principles of autonomy, beneficence, and nonmaleficence. Murphy's Nurse-Patient Relationship Models

Murphy described three ways that nurses view the nursepatient relationship: bureaucratic, physician advocate, and patient advocate. "I-it" nurse-relationships are a consequence of the bureaucratic and physician advocacy models. In them, the patient is seen as a thing to be manipulated or a means to further ends (Murphy, 1979, 1983). Bureaucratic model. The nurse's role is well defined and limited by her position in the bureaucracy; the physician is the leader due to position in hierarchy, education, and training, and patients are expected to know their roles and the limits of the nurse's role. The goal of this model is to maintain the social order of the institution at the expense of the individual patient's welfare. Emphasis is on teamwork with no consideration 
given to the individual responsibility and accountability of the nurse to the nurse-patient relationship (Murphy, 1979, 1983) •

Physician advocacy model. In this model, the nurse is an extension of the physician, enhancing the authority of the physician. The nurse-physician relationship is seen as more important than the nurse-patient relationship, and the nurse's duty is to promote trust between the physician and patient. The goal is to maintain trustful and harmonious relationships between nurse and physician and between patient and physician, even at the expense of the nursepatient relationship (Murphy, 1979, 1983).

Patient advocacy model. In the patient advocacy model, the nurse's first responsibility is to and for the patient. Care is determined by the patient's needs. The nurse's moral authority is as important as the authority of other health care professionals. The nurse is not an extension of the physician. Nurses and physicians are responsible for their own actions, and nurses control their own goals and command their own morality and ethics. The goal of the model is acceptance of the patient as a unique human being, while the role of the nurse is to be the patient's advocate and facilitate the patient's efforts to obtain care needed, even if in disagreement with the physician or institution (Murphy, 1979, 1983). 
Gadow's Models of the Nurse-Patient Relationship

Gadow's models of paternalism, consumerism, and existential advocacy are deeply rooted in ethical theory and principles. Gadow's models have been credited in subsequent model development (Smith, 1980) and in operationalizing the advocacy component of helping a patient decide (Corcoran, 1988).

Paternalism model. According to Beauchamp and Childress (1983), paternalism derives from the ethical principles of beneficence and nonmaleficence. Beneficence takes priority over self-determination (autonomy) when the conception of benefits, harms, and balances differ between the professional and the patient. According to Gadow (1979, 1980), the underlying assumption is that the professional is better qualified than the patient to define benefit and harm. Judgment is a professional, not a patient, decision. Paternalism implies the use of force or coercion to promote the patient's best interests and the failure to respect the patient's wishes or refusal.

Beauchamp and Childress (1983) and Gadow (1983) state that heiseficent infringement on patient freedom and selfdetermination is justified if the person's exercise of liberty would cause harm to others or if, as a result of limited capacity to choose wisely, the patient may be harmed as a consequence of his or her own choice. In the paternalism model, professionals are empowered by society to 
enact a parental role towards patients. Professionals act in the patients' best interests when they deem that what the patients desire is contrary to the patients' best interests thus protecting them from harm. Gadow (1983) asserts that autonomy is not recoverable once it is relinquished.

Consumerism/Patient Rights Model. Gadow maintains that consumerism is the opposite of paternalism and beneficence. The nurse assumes strictest neutrality to avoid influencing the patient's decision making. It is presumed that the nurse has no desire to assume decision making; the disengaged nurse supplies the patient with the facts, then withdraws, leaving the decision entirely to the patient (Gadow, 1980, 1983). There is no active involvement with the patient as there is in the existential advocacy model. Existential Advocacy Model. Gadow's existential advocacy model is a philosophical extension of advocacy and existentialism. Going beyond the basic defense of patient autonomy and freedom of self-determination, the Gadow advocacy model views the relationship between nurse and patient as a partnership. This partnership involves the nurse's participation and involvement with the patient as a means of enhancing the patient's autonomy. Explaining information, examining available alternatives of action, and assisting the patient in clarifying his or her own beliefs, values, and goals are objectives of this model. The patient determines the selection of information desired and the 
relevance of values and feelings. In the ideal relationship, both nurse and patient are commensurately equal in involvement and disclosure of values, although the patient's values will remain the ultimate decisive ones. The result of existential advocacy is the expression and, perhaps, health care decision that reflects the personal concept and meaning of health, illness, or death for that particular individual (Gadow 1979, 1980, 1983). Smith's Nurse-Patient Relationship Models

Smith (1980), who indicated she was influenced by Gadow's work, developed three models: nurse as surrogate mother, nurse technician, and contracted clinician.

Surrogate mother. In this model the nurse is committed to the patient as a surrogate mother. The patient's humanity has been damaged by illness or injury, and a loss of independence and freedom is experienced. The patient has decreased ability to make choices and, therefore, "mothering" is needed.

Technician. The nurse as technician is derived from the view of nursing as a clinical science, applying scientific methods and treatments in the care of patients. The nurse is highly committed to meeting the patient's needs through technically accurate care. If the patient is able to make decisions, he or she retains ultimate responsibility for identified needs and determines own best interests. The nurse has no role in determining client interests or needs, 
neither attempting to influence nor refusing to help the client attain goals. The nurse applies knowledge and technical skills as requested by clients and provides them with the information and technical advice needed to make decisions concerning their own health. Smith further states that, if the nurse's responsibility includes protecting the client's interests as determined by the client, then the nurse's role is that of an advocate. Smith (1980) conceptualized this image as Gadow's consumerism model. Contracted clinician.' The nurse as contracted clinician model is based on the existential advocacy model of Gadow. It postulates that the nurse-patient relationship arises from an agreement between nurse and patient and that the patient controls both the care to be received and the role taken by the nurse to provide it. The nurse is not ethically neutral and, therefore, can refuse to participate based on values and beliefs (S. Smith, 1980). Kohnke's Advocacy Model

Kohnke $(1980,1982)$ described the advocacy role of the nurse in the nurse-client relationship, here labelled as Kohnke's advocacy model. She developed no other models of the nurse-client relationship. The nurse has two functions within the role of patient advocate--to inform and to support. Kohnke cautions against zealous advocacy where the advocate becomes a rescuer, which then is paternalistic. 
The nurse informs patients of their rights and ascertains that they have all necessary information to make an informed decision. Advocates must be constantly on guard not to allow their own biases and values to encourage a decision not based on the client's own rational reasoning. Although the nurse does not take an active role in the actual decision making, once the patient makes a decision, the advocate supports that decision, even if disagreeing that it is in the patient's best interest (Kohnke, 1980, 1982).

A Comparison of the Nurse-Client Relationship Models

Cole Schonlau (1989) identified strong and weak conceptual relationships between some of the models proposed by Murphy (1979, 1983), Gadow (1979, 1980, 1983), Smith (1980), and Kohnke (1980, 1982). Figure 1 provides a schematic representation of the relationships described by Cole Schonlau (1989).

As illustrated by the dashed lines in Figure 1 , elements of Murphy's bureaucratic and physician advocacy models and Smith's surrogate mother model weakly relate to Gadow's paternalism model. The client is denied the status of being a unique human being in both Murphy's bureaucratic model and the physician advocate model. In the former model the goal is to maintain the social order of the institution, and in the latter nurses subjugate themselves to the goal of maintaining trust and harmonious relations between nurse and 


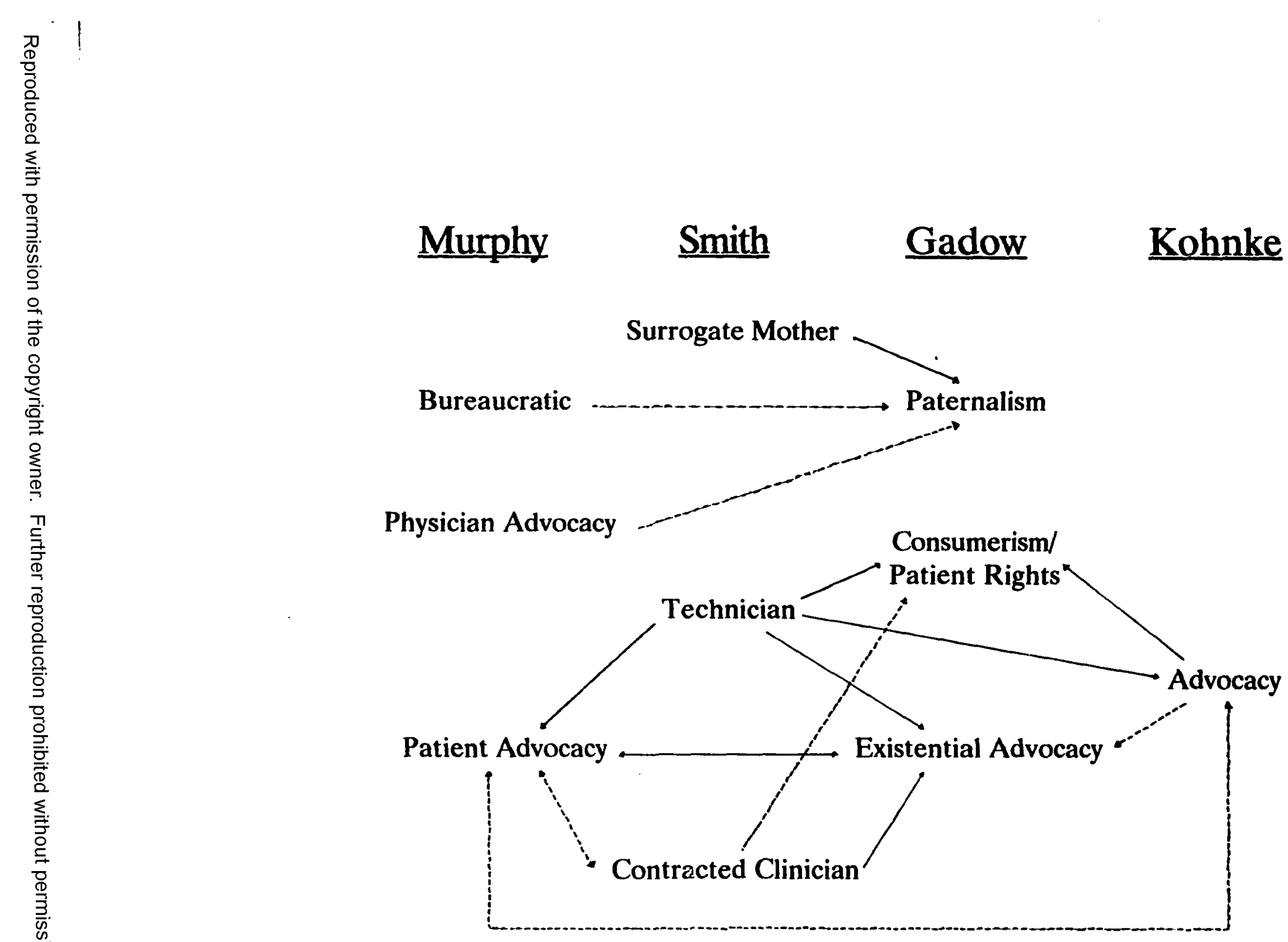

Figure 1. Affiliations Between the Models of the Nurse-Client Relationship 
physician and client and physician. Likewise, Gadow's paternalism model, in which the professionals judge the benefits and harms and determine what decision is in the best interest of the client, does not consider the client's uniqueness. Smith's surrogate mother model strongly relates to Gadow's paternalism model, as indicated by the solid lines in Figure 1. The nurse mothers clients because their humanity has been damaged by illness or injury or their confinement has caused a loss of independence and freedom, thereby diminishing their ability to make choices and increasing the possibility of paternalistic behaviors by professionals.

Similarities and differences were noted between the different models professing client advocacy (Cole Schonlau, 1989). Murphy and Kohnke would agree that the nurse's fundamental responsibility is to and for the client and would accept the client as a unique human being. Murphy believes that facilitating the clients efforts to obtain needed care is a function of the role of advocate. Both recognize the element of risk nurses take as intermediaries or intercessors when there is disagreement with the physician or institution. Kohnke (1982) elaborates upon risks associated with advocacy, such as conflict with physicians and institutions, lack of support by peers or supervisors, and possible social and disciplinary recriminations. These inherent risks which may act as 
deterrents to nurses' utilization of the advocate role, need to be recognized and carefully considered (Cole Schonlau, 1989).

In contrast to Murphy and Kohnke viewing the client as primary in the nurse-client relationship, Gadow's existential advocacy model and Smith's contracted clinician model picture the nurse-client relationship as an equal partnership between nurse and client in which the client determiles what role, participation, or involvement the nurse will have in the client's health care. Both refer to the nurse's involvement with the client; however, Smith goes further, adding that the nurse is not ethically neutral and can refuse to participate based on values and beliefs (Cole Schonlau, 1989).

Kohnke's model of advocacy relates to the other three models only in relation to the role dimensions of informing and supporting. Whereas Murphy, Gadow and Smith would agree that these two functions are part of the advocacy role, Kohnke postulates that informing clients of their rights and ascertaining that they have all the necessary information with which to make informed decisions and then supporting their decisions are the only two components of the advocate role. In Kohnke's model the nurse does not actively participate in client's decision as in Gadow's existential advocacy model. Moreover, it relates very strongly to Gadow's consumerism/patient rights model in which the nurse 
supplies the client with the facts and then remains completely neutral by withdrawing in order that the client's decision be made without any influence by the nurse (Cole Schonlau, 1989).

Smith's technician model agrees with both Gadow's consumerism/patient rights model and Kohnke's advocacy model. The premise of the technician model is that clients make their own decisions without the nurse either influencing nor refusing to help clients attain their goals. The technician model also relates to Murphy and Gadow's advocacy models in that, if clients determine their interests need to be protected, the nurse has a responsibility to act as advocate (Cole Schonlau, 1989).

\section{Empirical Background}

Several research studies have been conducted to investigate advocacy and the nurse-client relationship from the nurse's perspective. In a survey of 12,500 nurses, Sandroff (1981) found that nurses have a positive attitude toward client advocacy and consider the rights of clients before physicians. Because of their increasing clinical expertise, nurses felt they had a moral responsibility to defeid cijents' rights and to keep them well informed.

Bell (1987) investigated client advocacy in nursing from the perspective of registered nurses in the state of Virginia. Data analysis revealed that nurses recognize the need for the client advocacy, yet lack consensus in defining 
the role. Poor nurse-physician relationships and lack of full-fledged professional status for nursing contributed to the lack of consensus in defining the role and in effective enactment of the role.

In a phenomenological study, E. Smith (1987) identified seven essential constituents of the nurse-patient relationship as experienced and described by the nurse. They are recognition of the patient as an holistic being deserving of respect and value, concern for the patient's welfare, patient advocacy, patient education, interaction with the patient's family, physical care, and recognition of the nurse's role and responsibilities toward patients.

As previously noted, interactions are the basis of the nurse-client relationship. In an anthropological study, Allen (1981) observed and described 50 person-to-person interactions between ten registered nurses and their patients in a 60 bed acute care hospital. of the resulting five categories of interactions, ten were empathetic, nine were responsive, nine were perfunctory, seven were reassuring, and fifteen were unresponsive. The study concluded that the interactions of nurses with their patients were neither routine nor stereotyped because nurses interacted in many different ways with the same patient and with different patients.

Baer and Lowery (1987) examined nurse-client interaction and the affect of particular patient 
characteristics and situational factors on nursing students' positive or negative feelings about caring for patients. In their study, 140 baccalaureate students responded to an investigator developed opinion questionnaire regarding caring for patients. The results indicated that nursing students most liked caring for patients who were cheerful and communicative. They also liked patients in pain, patients needing high levels of nursing care, and patients responding positively to the student's attempts to provide care.

To protect their autonomy in health care, clients must be ensured the information necessary to make informed decisions regarding their care. Benner (1984) described information giving as part of the teaching/coaching function of the nurse, and study results indicated that nurses recognize that clients need and want information related to procedures they require and experiences they undergo. Nurses use advocacy when interpreting information between physicians and clients and when running interference between client and family. Benner cautioned that nurses must assess how much information the client wants and needs and communicate in a way the client comprehends. She further indicated that nurses must acknowledge the limits of their own understanding.

Two studies compared medicine and nursing's orientation toward informed consent and the nurse's role in providing 
adequate information for client decision making. In a pilot study of how health professionals view the role of nurses in providing information to patients, Davis and Jameton (1987) studied the attitudes of senior nursing students and fourth year medical students. They found that more nursing students than medical students favored nurses disclosing information to patients. Nursing students felt patients should not put automatic trust in the physician and patients should be allowed to think independently regarding treatment decisions. Although medical students disagreed, the researchers concluded that the disclosure of information by nurses may facilitate patient participation in decision making.

Carney (1987), comparing the perceptions of physicians and nurses in a Bone Marrow Transplant unit on informed consent, found that physicians focused on outcome, while nurses felt the patient should be completely informed about the side effects and attendant risks of treatment before consenting. The physicians perceived the nurses' role as patient educator; the nurses focused on patient advocacy in assessing patient knowledge, adding clarification to physician explanations, and encouraging the patient to discuss any concerns. The nurses had positive perceptions of patient rights and were positive toward utilization of the client advocate role. 
In an ethnographic study of a pediatric bone marrow transplant team, fidelity emerged as the central ethical principle guiding caregivers in relating to patients and families (Marsden, 1988). Four implicit promises were identified within the nurse-child/family relationship: the promise to attempt cure, to care for the child physically and psychologically, to treat the child and family with dignity, and to stand by the child and family in the process of death. Two of these promises relate directly to advocacy in the nurse-client relationship, the promise to treat with dignity and the promise to care. The researchers concluded from the findings that the nurse often acts as an advocate for the child by protecting the child from medical procedures secondary to physician research protocols that the child or family wishes to decline and facilitates negotiations between team members regarding the child's activities. The nurse protects the child from outsiders not acting in the best interests of the child by reporting inappropriate behavior, and the team tries to keep the child's wishes in mind during decision making.

Nurses' and Clients' Perceptions of the Nurse-Client Relationship: Empirical Comparisons

Two studies compared nurses' and clients' perceptions of a nurse-client relationship. Pluckhan (1970) investigated the quality of the nurse-client relationship in the home health setting using, as a research design, Carl 
Roger's theory of a therapeutic relationship, which is based on a patient-centered approach with respect for the worth and capacity of the individual to be self-directed. The subjects were 30 visiting nurses and 30 clients evenly selected from low, middle, and upper socioeconomic classes. Nine trained judges assessed three minute segments of audiotaped visits using a condition scale for each of three attitudinal conditions to rate the degree to which the conditions existed in the relationship. clients' perceptions of the relationships were measured by the Barrett-Lennard Relationship Inventory. Results indicated that only 2 of the 30 nurses established a therapeutic relationship with their clients based on the judges' perceptions of the interactions, although the clients' perceptions of the relationships were highly favorable. Nurses utilize patient education in the advocate role. Tilley, Gregor, and Thiessen (1987) found incongruence between nurses' and clients' perceptions of patient education by nurses when they investigated the similarity between 38 maternal nurse-patient dyads concerning the nurse's role in patient education. Although patients identified a general teaching function for nurses, clients preferred to have their physician teach them specific information related to their condition. Nurses had incorrectly assumed that patient education would be the client's first choice and that the client's desire for 
patient education was similar to their own. Tilley et al.'s findings have significance for this study: nurses view both patient education and advocacy as important aspects of the nurse-client relationship and assume that advocacy is similarly desired by clients.

Advocacy and the Nurse-client Relationship: The Client's Perspective

Exploration of the literature revealed that the client's perspective of advocacy associated with the nurseclient relationship has not been investigated. Researchers have explored client participation in health care decision making, client expectations, and client satisfaction with nursing care behaviors, including elements of advocacy. client desire for exercising autonomy in decision making is related to client advocacy and therefore relevant for inclusion here.

\section{Client Participation in Health Care Decision Making}

Client participation in health care decision making has been discussed in the literature in relation to advocacy. It is said that clients have a basic human right to be involved, to participate, and to make decisions that affect their own health care (Sparrow, 1978). How much involvement do clients actually want in health care decision making?

Physicians and nurses have conducted several studies on client participation in decision making. Strull, Lo, and Charles (1984) investigated clients' desire for information, 
discussion, and participation in decision making as well as their physicians' perceptions of same. Research findings indicated that clients of nurse practitioners and pharmacists believed they received more information than did clients of physicians. The researchers discussed supporting studies that indicated clients receive little information from physicians and want more.

strull el al. (1984) also indicated that research findings conflict in client desire for decision making. Results indicated that more than $50 \%$ of the clients wanted at least some participation in decision making, $33 \%$ preferred that the clinician make the therapeutic decision but strongly consider client opinion, and $19 \%$ wished to share equally in decision making. Only $3 \%$ wanted complete control, and $47 \%$ preferred that the clinician make the therapeutic decision without client participation. The researchers found that clinicians underestimated the clients' desire for making decisions, concluding that each client needs to be assessed for preferences and physicians need to individualize their approach to meet client desires. They did not, however, offer suggestions on how to accomplish this.

In a study on client participation in decision making, Wolf (1988) found that information dissemination is essential because mere participation understated the client's role. He also found that client participation may 
be routinely overridden by the physician. He suggests that presentation of alternatives and information to the client and open communication between client and physician lead to collaboration and partnership in decision making.

Eraker and Politser's (1982) research results indicated that although disseminating information and presenting alternatives to clients are important, successful communication seems to depend heavily on the way the information is presented. The investigators indicated that, to better serve clients' best interests, health care professionals must understand the way clients perceive and evaluate medical risks and benefits and must closely monitor how they present the information.

Dennis (1987), investigating what activities clients perceive as control-enhancing during hospitalization, found mixed results of client desire to participate in health care decision making. Some clients wanted more information about tests and treatments but did not desire active involvement in decision making; on the other hand, other clients wanted an active decision-making role and were less concerned about hospital environment controls.

In a field study to obtain information on the types of nursing care decisions nurses make and the degree of client collaboration in such decisions on a medical/surgical unit, Kim (1987) noted collaboration in approximately $15 \%$ of situations. She postulated that nurses seemed to believe in 
collaborative decision making as a value in nursing practice, yet collaborative decision making was not feasible. She also postulated that lack of an institutionalized process for nurses to include clients in decision making in acute-care settings or situational factors such as routine tasks, pressures of time, and acuteness of situations were constraints to collaborative decision making.

In a second study, Kim (1987) described clients' perceptions regarding their own participation in the formulation of care plans and satisfaction with nursing care received. Data analysis suggested that, while most clients believed in their collaborative rights, very few clients perceived that they had participated in decision making. Those clients who perceived having had the greatest collaboration tended to be more satisfied with their nursing care than clients who perceived not having collaborated at all.

Kim (1987) further described the effects of two levels of collaboration in decision making regarding the manajement of pain. In this third study, Kim found a tendency for those clients in the high collaboration group to have higher satisfaction with care than clients for whom nurses managed decision making as routine practice or clients in the low collaborative mode. 


\section{client Satisfaction with Nursing Care Behaviors in the Nurse-Client Relationship}

Several investigators examined nurse-client relationships and client satisfaction with nursing care behaviors. In Bader's (1988) investigation of nursing care behaviors that lead to client satisfaction, adult medical/ surgical patients indicated that they were least satisfied with the patient education dimension of nursing care behaviors, mentioning that they wanted more information from the nurse on results and treatments and wanted to be kept updated so that they could more actively be involved in making health care decisions. Helpfulness, friendliness, and interpersonal skills were rated highly.

Using both an open-ended question and the caring Behaviors' Assessment, Cronin and Harrison (1988) identified nursing behaviors perceived as indicators of a caring nurseclient relationship by 22 patients post myocardial infarction in a coronary critical care unit. Nursing actions that focused on physical care and monitoring of patients were seen as most indicative of a caring relationship. Assessment activities and demonstration of professional competence were viewed as significant expressions of caring. Teaching was perceived as significant, but individualized aspects of care were seen as less important in the critical care setting. 
Magilvy, Brown, and Dydyn (1988) conducted an ethnographic study to gain an understanding of the experience of home health care from the perspective of nine frail elderly clients. Three themes related to the home health care experience emerged: nursing care, health problems, and independence. In addition, clients emphasized the importance of reassurance and support by nurses. Teaching was not readily identified as part of the nurse's role, and home health care was perceived to support dependence and hinder return to self-care.

An exploratory, descriptive-comparative approach was used in a Canadian maternity labor and delivery study to investigate the differences in client satisfaction between 24 families in birthing rooms and 20 families in traditional settings (Field, 1987). The findings indicated that the characteristics of the nurses, not the labor and delivery setting, created the feelings of client satisfaction with care and the labor and delivery experience. Characteristic nursing behaviors identified as satisfying to clients were friendliness; parent advocacy and intervention with the physician to express the parents' wishes; demonstration of knowledge; the ability to make parents feel at ease, to listen, and to convey respect for parents; competency in care provided; and individualization of care to parent needs. 
Drew (1986) explored clients' experiences with caregivers' excluding and confirming interactions in a phenomenological study. She found that clients felt depersonalized and excluded when their feelings were disregarded by the nurse. Those who described confirmation and positive experiences depicted such nurse characteristics as caregivers who expended energy on their behalf and took time to smile and joke with them. In addition, touch conveyed information about caregivers as persons, and a low, modulated, and animated tone of voice and clearly enunciated speech conveyed emotional warmth.

Summary

This chapter reviewed literature related to the phenomenon of advocacy, from the professional perspectives of law, social work, medicine, and nursing. Theoretical and empirical literature in nursing focused on advocacy in the nurse-client relationship from the nurse's perspective. Four models of the nurse-cilent relationship were examined. In addition, literature related to advocacy and the nurseclient relationship from the client's perspective, including dissemination of information, participation in decision making, and client satisfaction with nursing care behaviors was presented.

A wide variety of nursing care behaviors that could be expected in the nurse-client relationship were described as satisfying to clients. Nurses need to know what clients 
expect and desire from nurses. The literature written about advocacy and the nurse-client relationship revealed primarily the perspective of the nurse. Much of the literature was theoretical, and the empirical literature scant. A paucity of research addressed the client's perspective of advocacy associated with the nurse-client relationship and experiences with nurses as client advocates. Therefore, investigation into this area of importance was timely and appropriate. 


\section{CHAPTER THREE}

\section{METHODOLOGY}

This chapter includes descriptions of why the phenomenological method was appropriate for this study and the research design of this investigation. Study participants and their protection as human subjects, data collection, and validity and verifiability of data are included. The procedure used for phenomenological data analysis in this investigation concludes the chapter. Phenomenology as an Appropriate Method Phenomenology is the most appropriate methodology to investigate lived experiences of clients as perceived and described by the clients themselves. Phenomenology leads to understanding and explaining the human experience (Omery, 1983) when little is known about the phenomenon or when research is lacking on the subject (Field \& Morse, 1985). As previously noted, literature reveals a paucity of research on advocacy associated with the nurse-client relationship from the client's perspective. Scientific progress cannot be made in investigating and understanding a phenomenon without first disclosing the foundation of the phenomenon (Colaizzi, 1978). Therefore, it was most appropriate to use the phenomenological approach in this study . 
In addition, the nurse-client relationship is primarily a social and interpersonal activity between the nurse and client (Davis, 1978), and phenomenology as an empirical methodology can give a fuller and fairer account than a quantitative approach could accord because no research has been conducted per se (Munhall \& Oiler, 1986; Oiler, 1986; Omery, 1983). Phenomenology can be summarized as the rigorous (systematic and methodical) inquiry and description of human experience. Hence, the essential characteristics of advocacy associated with the nurse-client relationship as described from the experience of the client was best clarified or discovered through the holistic methods of phenomenology.

\section{Research Design}

This was a phenomenological study to describe the essential characteristics of advocacy associated with the nurse-client relationship from the client's perspective. The aim was to understand the phenomena, to make explicit what was implicit, rather than to explain, predict or control the phenomena (Valle \& King, 1978; Zaner, 1970). By investigating the client's experience with the phenomenon of advocacy in the nurse-client relationship, this phenomenological study sought to return to what Husserl (1965, 1970) referred to as "the thing itself" (the true essence of a phenomenon). The design was exploratory in nature, seeking to discover new knowledge (Giorgi, 1985) 
that will enhance the understanding of advocacy in respect to the nurse-client relationship.

Knowledge of clients' lived experience becomes known through their descriptions of the meaning of the reality for them (Merleau-Ponty, 1964). By describing their experiences, we can bring nursing's thinking closer to experiencing the clients' perceptions, to make concepts more accurate, more precise, and closer to the reality of the experience (Oiler Boyd, 1989). Knowledge about a concept and knowledge gained by experiencing a concept are not the same (Salsberry, 1989). The aim of phenomenology in this study was to disclose advocacy in respect to the nurseclient relationship as experienced by the client, not as the concept was understood by the client. By describing the essence of the experience, the experience can be transformed into a concept (Oiler Boyd, 1989); phenomenology therefore provided a means of uncovering knowledge of the essential structure of the concept of advocacy as experienced by clients (Salsberry, 1989).

\section{Study Participants}

Due to the length of the interview process and the detail of the complete descriptions, the sample size for this study was ten. The adequacy of the description which results from the data analysis is due not so much to the size of the sample but to the depth of the interviews (Bogdan \& Taylor, 1975). Each participant's verbal 
description was a complete account of the experience of the nurse-client relationship and as such illustrated the essential characteristics of advocacy associated with the nurse-client relationship.

Two criteria suggested by Bogdan and Taylor (1975) and utilized in selecting participants were a firm commitment on the part of the subject to see the project through to the end and the ability and willingness to verbalize past and present experiences and feelings. Additionally, participants were at least 18 years old (to give legal consent), spoke English, and had had a professional experience with a registered nurse within the previous six months (so that the experience was still clear).

Volunteers were solicited in the following manner. Verbal contact was made with several professionals in the health care community to apprise them of the study. They were told that the researcher was interested in studying the client's perspective of the nurse-client relationship as well as the criteria for participation. Being "truthful but vague" (Taylor \& Bogdan, 1984), the relationship to advocacy was not explicitly stated in describing the purpose of the research to participants so that any experience they had with the advocacy of a nurse might be described without prompting.

Verbal contact was followed by a letter explaining the purpose of the study and the criteria for participation (see 
Appendix A for sample letter). The letter requested that the information be shared with clients and that the names of volunteers who expressed an interest and a means of contacting them be forwarded to the researcher. Individuals were selected from these referrals. The first ten individuals contacted met the criteria for participation. Volunteers were told that the researcher was interested in their perspective of their individual experience with nurses. They agreed to be interviewed and consented to the interviews being taped. Participants were told that the interviews were expected to be one to two hours in length and that more than one meeting might be necessary. Participants were also informed that they could withdraw from the study without prejudice at any time during the interview, should they not wish to continue. Additionally, the anonymity of all participants was maintained. Only the investigator was able to identify the participants: all personal names were deleted from the interviews, and any other identifying information was removed; furthermore, all interviews were coded, and the list of names and codings was known only to the researcher. Prior to the actual interview, all participants were asked to sign a consent (See Appendix B). Confidentiality of all data, such as tapes, transcripts, and informed consents, has been maintained by keeping them locked in a desk drawer to which only the 
researcher has access. The University of San Diego requires that all informed consents and data be retained for a period of five years. Therefore, they will continue to be secured in a locked file at the conclusion of the project for the designated time and will then be destroyed.

Data collection

Data were gathered via the interview process, and all interviews were tape recorded for later verbatim transcription. During the transcriptions, the researcher added any data, such as noriverbal body language, observed during the interview that might have added meaning to the verbal discussion.

Interviews were arranged at times and places mutually convenient to both participants and the researcher. All interviews took place in the participants' homes except one, which was conducted in the participant's office at work. Although interviews were scheduled for one hour, the actual duration of the interviews depended upon the interviewer and the participant and ranged in length from 50 minutes to over three hours, the majority being 60-90 minutes. The researcher met with each participant until the researcher and participant felt that the total experience had been described. The researcher organized her schedule in order to allow interviews to continue longer if needed or desired by participants. At the end of the first interviews for nine participants, the researcher and participants felt that 
the descriptions were exhaustive, and therefore no further interviews were scheduled. An additional session was arranged with one participant. One of the interviews concluded in less than one hour because both participant and researcher felt that the experience had been completely described and that further discussion would have been redundant. Additionally, one of the participants called the researcher after the interview and over the phone gave further information about her experiences.

General theme questions guided the interviews, but follow-up questions to probe and clarify information were individualized and unstructured. These unstructured interviews enabled the discovery of the participant's experience of advocacy in the nurse-client relationship (Lofland \& Lofland, 1984). By proceeding without any preconceived view of the specific content or flow of information to be gathered, the researcher was able to elucidate the respondents' perceptions of the experience without imposing any of her own views on the participants (Polit \& Hungler, 1989). The questions changed as the interviews progressed and the researcher discovered what questions elicited the richest data to "solve" the research problem. Allowing for immediate follow-up questions for clarification was a strength of these qualitative in-depth interviews (Marshall \& Rossman, 1989). 
Schatzman and Strauss (1973) asserted that interviewers should initially set the stage for interviews with a general statement, a substantive theme or a topical outline of several themes to prepare participants for what is to follow. For this study, each interview was initiated with this same open-ended theme question:

I am interested in understanding the patient's perspective of the nurse-patient relationship. You are participating in this study because of your recent experience with a nurse. Please choose a specific situation in which you and a nurse had a professional relationship and tell me everything about it. Tell me what happened, what you thought about it, and what you felt about it. Please do not stop until you believe you have described all of your thoughts, all of your feelings and perceptions as completely as possible.

During the researcher's interactions with the participants, the term patient was used rather than client because most individuals are more familiar with the term patient when interacting with nurses. From the initial general questions, additional questions flowed from the individual participant's responses, thereby clarifying and expanding on the descriptions supplied. Follow-up questions included: 
1. What in the experience made it a successtul and satisfying one to you?

2. What was missing that you felt should have been present?

3. Tell me anything you can about the nurse's behaviors which met your expectations.

4. Were there any other expectations of the nurse that you had going into this experience that we have not talked about?

5. If the description of the nurse-client relationship did not include advocacy and the follow-up and probing questions did not elicit any description or reference to advocacy, the following direct question was then posed: Were there any instances in which the nurse was an advocate for you? Please describe any behaviors or actions on the nurse's part that indicated that the nurse was a) informing you of alternatives, b) helping you make a decision, c) supporting your choices and desires, d) interceding on your behalf with others, or e) defending your rights as an individual.

$$
\text { Validity and Verifiability of Data }
$$

Each qualitative methodology has its own rules concerning aims, evidence, inference, and verification (Sandelowski, 1986). The aim of phenomenology is to describe experiences and perceptions rather than to explain or interpret them (Oiler, 1986). Throughout the interviews, 
participants were observed for nonverbal indications of integrity and credibility of statements. Clarification of nonverbal appearances was sought if appropriate (e.g., "you appear uncomfortable..." or "you seem to hesitate when you speak about that incident...."), and reassurance or encouragement were offered appropriately. At the conclusion of each interview, the participant was asked to verify key words and phrases utilized in order to ensure that meanings were accurately understood.

Data Analysis

Data analysis is the process of bringing order, structure, and meaning to the mass of collected data and of searching for general statements about relationships among categories of data. The researcher did this by organizing the data, reducing the data into manageable chunks, synthesizing it, and generating categories, themes, and patterns from the data (Marshall \& Rossman, 1989). There are several interpretations of the phenomenological method of investigation. The specific method of data analysis used in this study was one described by Giorgi (1985). The process and result of data analysis included the core elements common to all phenomenological methods of data analysis: reduction, intentionality, the search for essences, and their description.

"Reduction" or "bracketing" occurred early in the research process when the researcher disengaged from and 
suspended a 1 judgments or "natural attitudes" in order to understand advocacy associated with the nurse-client relationship as the client experienced it. These preconceived judgments, the assumptions identified for this study in chapter 1, were made explicit and challenged by putting them aside and attending to the task of describing the essences of the phenomenon, explicating the various levels of meaning of the phenomenon to the participants, and the relationships between the essential characteristics (Stewart \& Mickunas, 1974; Zaner, 1970).

The procedure of data analysis described by Giorgi (1985) has five steps. The data were the participants' unstructured descriptions of the lived experience.

1. The researcher read the entire description in order to get a general sense of the whole statement.

2. Once the sense of the whole had been grasped, the researcher reread the text with the specific aim of discriminating "meaning units" of the experience being researched (Giorgi, 1985). These units together make up the whole meaning of the experience.

These "meaning units" are the authentic verbalizations, the significant statements given by the respondents. significant statements were identified in several ways: similar descriptions given by several respondents; statements that reflected previous descriptions of advocacy from the literature, including those behaviors offered in 
the Definition of Terms in Chapter 1; and emphasis placed by any individual respondent on a particular descriptor. These meaning units or significant statements were nighlighted in the transcriptions for later categorization.

Intentional analysis is the analysis of the meaning of the experience for the participant. It aided in uncovering the phenomenon and making it manifest and therefore understood by description within reduction (Giorgi, 1985).

3. The researcher eliminated redundancies of the significant statements. Eliminating duplicate statements enabled insight into emerging patterns and themes by decreasing the volume of data.

4. The researcher then clarified or elaborated on the meaning of the remaining units, still identified in the concrete language of the participant, by rereading the transcriptions and the extracted significant statements and relating them to each other and the whole.

5. Each description was analyzed in isolation from the others. Analysis of each description and its significant statements was completed prior to beginning data analysis of subsequent interviews. Significant statements were clustered into themes for each description; upon completion of all individual data analyses, the whole was reviewed again. The researcher reflected on the meaning units and then expressed or transformed that concrete language into 
the language or concepts of science (Giorgl, 1985; Omery, 1983).

5. Patterns of significant statements/meaning units common to all descriptions were clustered and reanalyzed for the entire picture. The researcher integrated and synthesized the transformed meaning units into a consistent statement about the participants' experiences. For this study, the descriptive structure of the meaning of that experience to the participants is the essential characteristics of advocacy associated with the nurse-client relationship from the client's perspective.

In phenomenological terms, these essential characteristics are also known as the essence of a phenomenon, the core meaning, structure, or characteristics that cannot be separated from the phenomenon without changing the phenomenon or making it disappear. In so far as the essential characteristics of advocacy associated with the nurse-client relationship were grasped through the lived experience of clients, they are concrete knowledge (MerleauPonty, 1964).

A structure of meaning of the lived experience, the conceptual synthesis of the meanings, constitute the results of a phenomenological study and enhances the understanding of common human experiences encountered in the life process (M. Smith, 1989). The results of this study are the comprehensive description of advocacy associated with the 
nurse-client relationship from the client's perspective. This final product will be communicated to other researchers through journal publication and professional presentations for scientific critique. 
CHAPTER FOUR

REPORT OF THE FINDINGS

A description of the study participants and the findings that resulted from the data analysis are included in this chapter. The client's perspective of the essential characteristics of advocacy associated with the nurse-client relationship is described, as is the relationship between the essential characteristics. A report of additional findings that emerged from the study data concludes the chapter.

\section{Study Participants}

The ten study participants were nonhospitalized adults or significant others over the age of 18 years who had had a professional relationship with a registered nurse within the previous six months. The ten subjects generated over eighteen hours of interview tapes that were transcribed into ten manuscripts totaling 964 pages. The six female and four male subjects ranged in age from 29 to 72 . All were caucasian with varied occupations. The demographic data are presented in Table 1. Nine of the participants described experiences with registered nurses during their own hospitalizations and during the hospitalizations of immediate family members. Two of these nine also described experiences with registered nurses in an ambulatory setting. 
One participant described and compared professional experiences she had with nurses during her son's multiple hospitalizations.

Table 1

Demographic Data of Study Participants

\begin{tabular}{|c|c|c|c|}
\hline Subject & Sex & Age & Occupation \\
\hline 1 & male & 72 & retired shipping coordinator \\
\hline 2 & female & 50 & school teacher \\
\hline 3 & male & 55 & physician \\
\hline 4 & female & 67 & retired school administrator \\
\hline 5 & male & 19 & $\begin{array}{l}\text { nonmatriculated college } \\
\text { student }\end{array}$ \\
\hline 6 & female & 45 & secretary, inactive nurse \\
\hline 7 & male & 70 & retired aerospace worker \\
\hline 8 & female & 35 & dental hygienist \\
\hline 9 & female & 68 & disabled, former housewife \\
\hline 10 & female & 38 & dental hygienist \\
\hline
\end{tabular}

Description of the Essential Characteristics of Advocacy Associated with the Nurse-Client Relationship From the Client's Perspective The clients in this study reflected the essential characteristics of advocacy associated with the nurse-client relationship as nurse attributes, behaviors, and actions. Some of the clients classified them specifically as 
advocacy, while others described the same attributes, behaviors, and actions but did not refer to the word advocacy. Advocacy by those nurses who exhibited it was characterized as integrated within the whole of the nurseclient relationship; it was not described or differentiated separately from other roles portrayed by nurses. Not all nurses demonstrated characteristics of advocacy as evidenced in client descriptions of experiences. The four essential characteristics of advocacy associated with the nurse-client relationship extracted from this study were eidetic, emerging as core elements in each of the participant's descriptions. The minor characteristics that constitute each of the essential characteristics were common to all or nearly all participants' descriptions.

The four essential characteristics of advocacy associated with the nurse-client relationship, and described by clients as attributes, behaviors, and actions, were labelled Competent Knower, Competent Doer, Humanizer, and Communicator. The Competent Knower was experienced in nursing practice, knowledgeable about the client's condition and needs, and capable. The three minor characteristics identified in the data, knowledgeable, experienced and capable, are found in Table 2. The Competent Doer was the second essential characteristic of advocacy. The competent Doer took action on behalf of the client, either by own initiative or at the request of the client, solved problems, 
acted as intermediary, followed through on the client's needs and desires, exhibited competency in technical and supportive skills, and took responsibility for care given by others under supervision. Four minor characteristics were identified and are located in Table 3. The Humanizer was the third major characteristic of advocacy associated with the nurse-client relationship. In relationships with client, family, and professional colleagues, the Humanizer was perceived as a personable, caring team member/leader who treated the client as a valued individual person, went the extra mile with extra efforts, made self available to client by his or her presence, encouraged, intervened on the client's behalf, and supported the client's decision. The seven minor characteristics which constitute the Humanizer are displayed in Table 4. The Communicator, the fourth essential characteristic of advocacy, transmitted and exchanged information with client, family, physician and other health care professionals. The Communicator served as a liaison between them, kept the client informed by disclosing pertinent information voluntarily and by request, educated, and provided explanations. The three minor characteristics are identified in Table 5.

Essential Characteristic: Competent knower

To reiterate, the three minor characteristics of the Competent knower indicated that the nurses who were client advocates were experienced in nursing practice, were 
knowledgeable about clients' conditions and needs, and were capable. Table 2 displays the minor characteristics of the Competent knower.

Table 2

Essential Characteristic: Competent knower - Minor Characteristics

1. Knowledgeable*

2. Experienced*

3. Capable

* Common to all descriptions

Being knowledgeable about the client's condition and needs and experienced in nursing practice were common to all descriptions of nurses displaying advocacy in their relationships with clients. The following statements are representative of how each participant indicated both knowledge and experience:

She knew what she was going to do and did it.

They all seemed to know exactly what they were doing; you get a feeling of great confidence and security.

Knowledgeable

Participants described various ways that nurses manifest their knowledge of the client's condition and needs. As one participant said:

She was on top of everything, on the ball. She knew what was going on: I felt I could ask her 
anything and she would have either known the answers or would have found out for me.

The nurse's cognitive skills of gathering and processing data may be made evident to clients, as illustrated by the following statement:

She was thinking and evaluating in her own mind what she saw. If she thought it was nearing time for the IV to come out, she went ahead and called.

One participant gave direct verbal confirmation that knowledge is an important element in the nurse's role as client advocate.

If the nurse saw a blatant wrong being done, a total incompetency, like the wrong medicine being given, she has to be a patient advocate. But it is a touchy, complex situation, it requires a lot of wisdom, each situation is different.

Several participants indicated knowledge of nurses' education in psychology. They verbalized the importance of the education component of nurses' knowledge in providing a foundation for client advocacy.

They have psychological training and can pick certain things out, initiate or direct some psychological help to certain people at certain times.

Education is better, not only a nursing license but the curriculum should include counseling and nursing because nurses help deal with people in bad situations, crisis situations.

\section{Experienced}

Experience in nursing practice is the second minor characteristic of the competent knower. The experiential component of nurses' knowledge is important in order for nurses to know what they are doing. Participants were aware 
of the clinical experience of nurses as indicated by the following:

Nurses are out there in the trenches and have that experience.

One participant described how a nurse's experience was made evident to him:

You get a more detailed, in-depth understanding of what you need, what you should do.

Another participant expressed how the nurse's knowledge and clinical experience had an impact on the care that was received:

She knows tricks that will make you more comfortable.

\section{Capable}

Knowledge and experience were evident to all. Several participants also discussed the nurse's capabilities in demonstrating that knowledge and experience of nursing practice. One participant described his experience with a nurse who explained why she was replacing his intravenous line and then did so quickly and without causing much pain:

I was impressed with her capabilities.

Several participants described the nurse's ability to illustrate knowledge and experience in overseeing serious clinical situations, expressed as:

I really felt she had the whole situation under control.

Being knowledgeable and experienced were minor advocacy characteristics of the competent knower found in all 
participant descriptions, while capability was described by several who expanded on how the nurse displayed knowledge and experience in the relationship. When nurses were described as capable, they were portrayed as self-assured, "being in control." A mental image was created by the descriptions; the Competent Knower was a nurse with straight posture and a calm, assuring voice whose knowledge, experience, and capability as a professional were demonstrated to the client through approach and performance. Essential Characteristic: Competent Doer Nurses who exhibited advocacy were perceived as Competent Doers, taking action on behalf of clients, either by their own initiative or at the client's request. They solved problems, served as intermediaries, followed through on clients' needs and desires, demonstrated competency in technical and supportive skills, and took responsibility for care given by others under supervision. Table 3 displays the four minor characteristics that constituted the Competent Doer. All participants described three of the four minor characteristics. 
Table 3

Essential Characteristic: Competent Doer - Minor

Characteristics

1. Competent in technical and supportive skills*

2. Took action as problem-solver and intermediary*

3. Followed through on client's needs and desires*

4. Displayed leadership/supervisory skills

* Common to all descriptions

Competent in Technical and supportive Skills

Clients described advocates as "good nurses" who were

competent in performance and actions. Being adept at

providing physical care and performing technical tasks was

always mentioned first in descriptions of competent

performance and actions. Clients described changing

dressings, checking for infection, taking vital signs,

giving medications, and making the client physically

comfortable before expressing other aspects of competent

nursing care and performance. Being competent and efficient

in both technical skills and emotional support was the third

common minor characteristic of the Competent Doer wherein

the nurse demonstrated the characteristics of advocacy. The

following significant statements supported competency and

efficiency in technical skills:

I liked her efficiency, skills, and take charge attitude. 
She was very competent in her behavior.

Physicals are embarrassing. She did it with such ease you don't know you're having a physical.

Participants also described the nurse who displayed advocacy in terms of the emotional support given to the client and family.

There is more to nursing than hanging bottles and giving the right medications, nurses need to provide emotional support.

They got right in there and knew exactly and gave information without asking.

She was very understanding, she did whatever there was to make you not feel sick.

Took Action as Problem-Solver and Intermediary

All participants perceived client advocacy as nurses taking action on the client's behalf as a problem-solver and as an intermediary with others. As a problem-solver, the nurse was described in the following ways:

Anytime I had a problem I could call her, she was always available and responded.

If something wasn't right, it was made right. If I didn't like the way something happened, it changed.

As an intermediary with others, the nurse was described as:

Responsible for the care and comfort of the patient, and the well-being of the patient, to the best of her knowledge, no matter what it takes, even if she has to make suggestions to the doctor that he may not agree with or to her supervisor.

The nurse is an intermediary between the patient and doctor and getting things done that the patient wants. She is also an intermediary between the patient and administration, not for one specific patient but for patients in general. 
clients verbalized that they may not always be aware of instances where the nurse took action on their behalf to solve a problem or meet a need.

Medicine is an amnesiac; a lot of times you're all drugged up so you don't remember the whole thing.

They [the nurses and doctor] worked together so I felt if she noticed something they would be right on top of it, that it would be taken care of immediately. The nurses were all coordinating.

If the nurse sees something that needs to be done that is not being done, she should tell the doctor. The patient may never know, that's not something you automatically go tell the patient, it could happen and $I$ ' would never know.

Clients recognized that risk-taking was a possibility with client advocacy. They indicated that risk-taking as intermediary should not to be taken lightly.

She's caught in the middle, she has to be careful and keep both sides happy. It's touchy for the nurse to be an advocate, it can jeopardize her position, jeopardize the people she works with.

Advocacy is not expected as ordinary, customary, routine because of the jeopardy involved.

Some clients, however, said:

She has an ethical obligation to be a patient advocate, if she sees something being done wrong, she needs to go above the doctor. If something jeopardizes the patient, it's her responsibility.

Followed Through on Client's Needs and Desires

The third minor characteristic of the competent Doer was common to all participants. Following through on clients' needs and desires again indicated the integration of advocacy within the whole of the nurse-client relationship. Nurses who exhibited the characteristics of 
advocacy followed through on clients' needs and desires by responding quickly to their needs.

When I called for something that needed taken care or, she took care of it right away.

They were there within minutes with whatever I asked for.

If I needed them, they came immediately and did whatever I needed to make me comfortable.

\section{Displayed Leadership/Supervisory skills}

All participants did not describe the last minor characteristic that constitutes the competent Doer. Nevertheless, most described registered nurses who exhibited advocacy as leaders who took responsibility for the care given by others whom they supervised. The nurse as leader and change agent was important to clients when they described nurses' utilization of their knowledge and experience and demonstration of leadership or supervisory skills in directing others or managing patient care. They also displayed these skills when interceding to correct errors and make changes after poor care had been provided by others. These changes may be known to clients as a followup on their requests or may remain unknown to them. Nurse leadership or supervisory skills were described in the following ways:

Put the patient who is really trying in a room with a cheerful person, not a miserable one who doesn't try to get better.

Her job was to see that patients were taken care of and to follow up on things not done by others. 
She needs to be a private detective, needs to check around and take care of complaints about nurse's aides without nurse's aides knowing you're telling on them.

Clients noticed nurses' work loads. For example, several participants commented on all the things they saw registered nurses do that could have been done by others. Participants said that, as nurse leaders and supervisors, registered nurses should delegate non-essential tasks to others. Voiced by many, one participant stated it this way: RNs should use their time with things that LVNs or orderlies can't do.

Participants described the attributes, behaviors, and actions of competent knowing and competent doing as essential characteristics of advocacy associated with the nurse-client relationship.

\section{Essential Characteristic: Humanizer}

The third major characteristic, the Humanizer, emphasizing the client's perceptions of the humanistic aspects of advocacy in the nurse-client relationship, was described far more frequently and in greater detail than the other essential characteristics. Clients perceived the Humanizer as a personable, caring team member/leader in relationships with client, family, and professional colleagues. The Humanizer intervened on the client's behalf, supported the client's decision, treated the client as a valued individual, encouraged the client, went the extra mile, and made self available to client by being there 
in presence. The minor characteristics of the Humanizer are found in Table 4.

Table 4

Essential Characteristic: Humanizer - Minor Characteristics

1. Caring*

2. Valued client as individual person*

3. Went the extra mile, made extra efforts*

4. Presencing*

5. Relating

6. Intervened on client's behalf/supported client's decision

7. Coaching

* Common to all descriptions

The first four minor characteristics listed above were identified in all interviews; participants discussed them in great depth. The next three were elements identified by nearly all and described frequently.

Caring

All participants described caring in great detail. Caring was perceived as an indispensable component of the humanizing characteristic of advocacy. The following are common statements made by participants:

She had the knack of putting the patient at ease in a frightening situation.

She took an interest in what I needed and wanted.

She made me feel special. 
She was kind and considerate, and gentle.

My nurse seemed concerned about my well being.

They were very caring, the feeling of support was evident.

I want nurses to really care about coming to work.

Participants always described nurses who demonstrated client advocacy as caring.

\section{Valued Client as Individual person}

Treating the client as an individual human being with rights and needs was another essential advocacy element of the Humanizer. Clients described this minor characteristic in detail. Participant support for feeling valued as an individual human being is found in the following examples:

She really got to know me.

You're really important to her.

She wanted to know more what the person wants over getting stuff that wasn't necessary.

At all times patients were cared for in a dignified manner, never subjected to abuse of any kind.

I was treated as really a person.

She treats them as human beings, not as a patient but as a human being who has all the same needs you have when you are well except the overlay of illness which colors everything you say and do.

She was accepting when I said I hurt a lot.

I was treated as a whole person in the hospital not just an incision.

Participants described valuing the client as a human being and as an person with individual needs and desires as 
requisite to the essential advocacy characteristic of Humanizer.

Went the Extra Mile, Made Extra Efforts

Every participant offered examples of nurses doing things for them that the participant considered above and beyond the call of duty. They also described this essential minor characteristic of advocacy as having one of the greatest impacts on their experience with nurses and as being the most positive remembrance of the hospitalization. Going above and beyond the normal routine expectations was always mentioned in conjunction to any reference to advocacy.

She'd go out of her way to try to please me. She did something extra, didn't have to.

She made extra trips into the room, asked if there was anything I would like, anything she could get me.

She offered me a backrub, what a luxury item. It was easy to sleep that night, it was extremely relaxing, very comforting.

She took extra pride in her job, what she was doing and how she took care of me.

She came back after duty and read poetry to me. Her patient advocacy was exceptional, not expected, but I would like to see more of it. Participants viewed going the extra mile and doing extra things for them as the highlight of their experiences. 
Presencing

Participants placed importance on the nurse's physical presence, the nurse's availability and responsiveness without necessarily saying or doing anything. Presencing was described in the following examples:

Just being there. Just being with the individual sick patient.

I felt she was really with me without saying anything.

Participants also described nurses as making themselves available to clients, taking time with clients, and not acting as if in a hurry, although they knew the nurses were busy.

They were always there if I wanted to ask them anything. They stayed and made me feel like we would finish the conversation before they left.

Her friendly, nonpressured approach made me feel secure that if I needed anything, she'd be right there.

Made each of us feel like she has time to spend just with us.

All participants viewed the nurse's presence and being available to clients as important in their descriptions of nurses who displayed the essential characteristics of advocacy .

Relating

The minor advocacy characteristic of relating refers to nurses being personable, teamwork, and developing relationships and with client, family, and professional colleagues. All participants described a positive 
personality in their experiences with nurses who related to

them in a humanistic manner.

They always spoke, were always friendly, always called me by name. They were cheerful, pleasant and smiled; makes you feel better when you see somebody with a smile on their face.

You could tell she really likes people.

One participant described the nurse's role in

developing the nurse-client relationship as a characteristic of advocacy:

The nurses took the initiative to develop the relationship.

Another participant described how having a consistent nurse facilitated a good nurse-client relationship:

Having a consistent nurse who knows me makes me feel safer, makes me feel more personalized, makes me feel more comfortable. You don't wonder what they're going to do. I'm less apprehensive, I know what to expect.

Several participants described teamwork among nurses and other health care providers.

They had a great working relationship.

It was most satisfying that a hospital could put together a group of people that would take care of you that well.

The nurses work close with the doctors.

The nurse and doctor worked as a team, on a more even level.

Likewise, participants discussed the relationship between nurses and clients and families as members of the team:

There was a special one-on-one interaction that went beyond a patient-nurse.

They encouraged the family to help. 
There was a sense of oneness with the family.

Some of the kids passed out trays.

Being personable, relating to others and working as a team are important humanizing characteristics of advocacy in the nurse-client relationship.

Intervened on Client's Behalf/Supported Client's Decision

The sixth minor advocacy characteristic of the

Humanizer focused on the nurse looking out for the client's interests and needs by intervening on behalf of the client or supporting the client's decision. Intervening on behalf of the client's interests and needs was described as:

The nurse is a gatekeeper, she made sure I had a chance to rest in between the respiratory therapist and the physical therapist.

When the patient is helpless and vulnerable, hardly holding it together, never mind fighting for their own rights or anything, if the nurse doesn't advocate for the patient, who does?

The nurse has an ethical obligation if she sees something being done wrong to go above the doctor.

The nurse advocate also supported the client's decisions and choices, as stated by one participant:

Once I decided, they were behind me. Once the patient has made up their mind what they are going to do, the nurse automatically says that's all I can do or if the nurse explained everything and the patient does not want to carry out the procedure, that's it, the nurse can't act in behalf but she is still being an advocate because she is supporting.

The nurse was described as supporting the client's decision, although few participants actually related having 
made decisions. Many indicated that they desired information and wanted to be kept informed; however, several said that, because the doctors and nurses were the experts in what their needs were for care, they accepted the decisions of the health care professionals.

They knew what I needed.

They knew what was wrong with him [son] and told me what they needed to do, there were no decisions for me to make.

Although many participants believed that it was appropriate for a health care professional to present a decision about care and treatment to the client without obtaining ample client input, clients complained about not being offered choices or alternatives about meals or snacks, or knowing that alternatives were available. Intervening on the client's behalf and supporting the client's decisions were seen as important characteristics of the Humanizer. Coaching

Several participants described coaching, the last minor characteristic of the Humanizer. The nurse advocate was characterized as a coach or cheerleader who both verbally and nonverbally encouraged the client to do well. Participants described nonverbal encouragement in the following ways:

Her facial expression said, "I hope so."

You felt like they were pulling with you. 
Cheerleading and coaching were visualized as personal aspects of care by many clients when they described encouragement offered by nurses. They recounted the deeply felt motivation resulting from this encouragement, whether it was in eating, exercising or pushing during labor.

She makes people feel good, perks you up.

She was almost like your mother, "Eat, eat." She was encouraging. She kept telling me I was doing good even though I didn't ask.

Just have one of those words, "Keep pushing, you can do it, you can do it."

Central to client advocacy are the humanizing aspects of the relationship between nurse and client, like "going the extra distance" and doing things that the client sees as "special," "extra," "not expected," "personal touches" that make the client feel special, "like they're the only one." Clients remembered these things long after incisional pain was relieved, vital signs returned to normal, and the return to normal everyday life. The humanistic aspects were the things that clients said they complimented when writing thank you letters to nurses and hospital administrators after discharge. They praised being treated with compassion and dignity, being treated as a valued human being, and as an individual whose specific needs and concerns had been addressed by nurses who demonstrated the characteristics of advocacy. The seven minor characteristics that constituted the essential characteristic, Humanizer, were extracted from 
the rich details of the participants' descriptions of the humanistic elements of advocacy.

Essential Characteristic: Communicator

The three minor characteristics that comprise the Communicator characteristic of advocacy indicated that the nurse transmitted and exchanged information with client, family, physician, and other health care professionals and acted as a liaison between them; kept the client informed by disclosing pertinent information voluntarily and by request; and educated and provided explanations. Table 5 presents the minor characteristics for the communicator. Table 5

Essential Characteristic: Communicator - Minor Characteristics

1. Communication liaison*

2. Explanation/education*

3. Information giving

* Common to all descriptions

All participants described two of the three minor characteristics, communication liaison and explanation/ education.

Communication Liaison

As a communication liaison, the nurse may intervene, coordinate, or mediate in transmitting and exchanging 
information between all members of the team (client, family, physician, and other health care professionals).

Participants said many things about this essential minor characteristic:

As a liaison, if she sees something that should not take place, she should be able to say, "We can handle this in a different way."

She is a liaison between doctor and patient and any other ancillary services.

Her interaction with the other RN was very encouraging. She gave her all kinds of information about me.

Two or three of them interacted, "we have this available, let's do this and call." Then they called the doctor.

They went into the patient's room to update the next nurse.

As a communicator with client and family:

She let my wife know how the operation was going. That helped her a lot, made her feel better knowing everything was going smoothly.

They told you who was who.

She said, "I'll be right back," and said what she would do when she came back.

Several participants explained the importance of communication skills, indicating the need for foreign educated nurses to speak good English to English speaking clients and the need for nurses to speak in nonmedical language understandable to clients, "translating" what the doctor and other health care professionals have said.

Communication skills should be emphasized.

They need to make sure the patient understands what they're saying. Some nurses have the 
tendency to speak in medical language which completely passes over the patient's head. She was very sweet and gentle but I had difficulty understanding her. She didn't speak English very well.

Strong team relationships are important for effective communication. Participants viewed communication as necessary in orienting clients to "who's who and what's where" when they are new to a facility and to be friendly and include them as members of the team. Explanation/Education

All participants described giving explanations, preparing for procedures, and providing educational information as the second common minor characteristic of the Communicator. They depicted nurses who displayed advocacy characteristics as being very good about providing explanations. As one participant said:

She explained everything she was doing and why. Regarding a nurse giving preprocedural preparation, one participant stated:

She prepared me that it was not going to feel good.

Participants described nurses providing general education in several ways:

She showed me how and I was able to do it. She reinforced the physical therapist, got me moving and explained the importance.

When she suggested things they made sense, she didn't suggest it in a way like I har to do it. 
Client education is essential to advocacy. The participants enthusiastically described desiring and receiving explanations, education and preprocedural preparation. They cite nurses as teaching or as "giving me information about" such things as what procedures the nurses were going to do, how to transfer from wheelchair or gurney onto a bed, what to expect when starting an intravenous line, and what to do to get better faster. Hence, explaining and educating were two ways that nurses demonstrated the communication characteristic of advocacy in the nurse-client relationship. Several participants described their experiences with discharge teaching. Few participants described actual discharge education by nurses; those that did described it in a similar manner to the following:

When I was ready to come home, she told me what was going to happen, what I had to do.

Many indicated that the doctors had given the home care instructions and discharge teaching and that there had been no elaboration by nurses. None identified a lack of home care instruction by nurses as being missed in their experience or seeming out of the ordinary. Information Giving

Information giving refers to keeping the client informed by disclosing pertinent information voluntarily and upon request. Three of the participants described information giving not as disclosure of information to keep 
the patient informed, but rather more in the category of explanation giving.

The importance of information disciosure and keeping the client informed either voluntarily or by request were described as characteristics of advocacy by seven participants.

She gave me information about the status of the infection.

If she has information she can pass on it can help the patient's well being.

She gave me information automatically about my vital signs, it was comforting.

All of these things [alternative actions] should be explained to patients beforehand. Sit down and talk to people before they get into real stress situations and let them make their choices.

Nurses need to give out information, not just be good at doing all the duties.

I want my nurse to voluntarily share information and answer questions, not be secretive.

Some people don't want to know anything. I like to be told. I do much better if I'm told what's going on.

Doctors are rarely there. The nurses know more about the patients than the doctors because nurses are there eight or twelve hours.

Clients stated that nurses need to share information with clients, and that they wanted nurses to give them more information. They characterized information giving as the nurse disclosing (providing) pertinent information voluntarily and by request to keep the client informed. Information disclosed included vital sign readings, 
changes/improvements in bacterial counts and grade of infection, and possible side effects of medications or treatments. Acting as communication liaison, explaining and educating, and disclosing pertinent information to keep clients informed were delineated as characteristics of the Communicator.

The Essential Characteristics of Advocacy

Associated with the Nurse-Client Relationship:

\section{Summary}

Four essential characteristics with minor characteristics of advocacy associated with the nurse-client relationship from the client's perspective were extracted from the data. Clients described these four essential characteristics, labelled as competent Knower, Competent Doer, Humanizer, and Communicator, as nurse attributes, behaviors, and actions. The competent knower was knowledgeable about the client's condition and needs, experienced in nursing practice, and capable. The competent Doer took action on behalf of the client, either by own initiative or at the request of the client. The competent Doer was a problem-solver, served as an intermediary, followed through on the client's needs and desires, demonstrated competency in technical and supportive skills, and exhibited leadership/supervisory skills that included taking responsibility for care given by others under supervision. In relationships with client, family and 
professional colleagues, the Humanizer was perceived as a personable, caring team member/leader who intervened on the client's behalf, supported the client's decision, and treated the client as a valued individual person. The Humanizer encouraged, went the extra mile by making extra efforts, and was available to the client by just being there in presence. As Communicator, the nurse advocate transmitted and exchanged information with client, family, physician, and other health care professionals, acting as a liaison, providing explanations and education, and keeping the client informed by disclosing pertinent information voluntarily and by request.

The Relationships Between the Essential Characteristics It can be concluded from the findings that essential characteristics of advocacy associated with the nurse-client relationship can be identified in the descriptions of lived experiences of clients. The major or conceptual characteristics and their relationships are diagrammed in Figure 2 .

To clarify, in their descriptions of experiences with nurses characterizing advocacy, participants placed the greatest emphasis on the humanizing characteristics, as evidenced by the rich details and emotionally ladened significant statements extracted and grouped under this characteristic. From the participants' perspective, it is concluded that the Humanizer is the most salient 


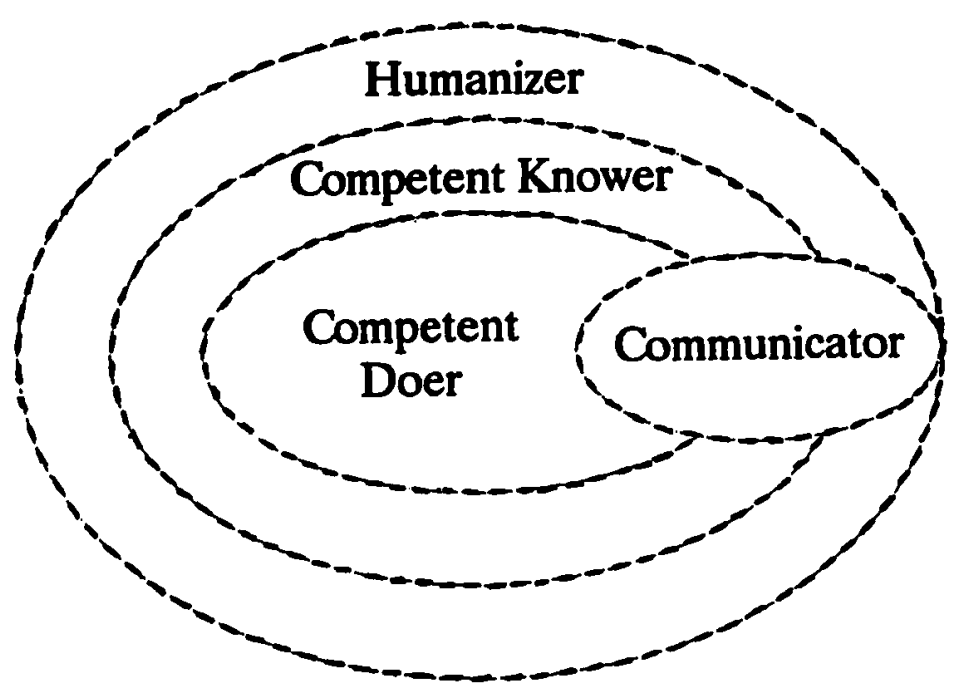

Figure 2. Relationships between the essential major characteristics 
characteristic and encompasses the other characteristics of Competent knower, Competent Doer and Communicator.

Competent knowing and doing were often described concurrently because the nurse needs to be competent in knowledge and experience in order to be competent in performance and actions. Therefore, the Competent Doer is subsumed within the competent knower.

Although described as a distinct characteristic, the Communicator relates to the nurse's competent actions, wisdom, knowledge, and experience demonstrated in effective communication, explanation, education, and information dissemination. The participants' descriptions demonstrate that an effective communication liaison must develop good relationships and be a caring, humanizing nurse who values the client's individual needs and concerns. Therefore, the Communicator relates to each of the other essential characteristics by traversing all three. An integrated relationship exists between all four of the essential characteristics, depicted by the dotted lines that "separate" them. This reflects the clients' perspective that advocacy is integrated within the whole of the nurseclient relationship and not classified or differentiated separately from other roles portrayed by nurses. These, then, are the four major essential characteristics that constitute the client's perspective of advocacy associated with the nurse-client relationship and 
the relationships between them. All of the minor characteristics can be clustered under one of these conceptual characteristics.

\section{Additional Findings}

Two additional findings worthy of reporting emerged from the descriptions. Nurses portrayed in the clients' negative experiences lacked advocacy characteristics. This description is followed by a report of client desire to be self-sufficient and not dependent upon the nurses.

Negative Experiences: Description of Nurses who Lacked Advocacy

All participants described at least one negative experience with a registered nurse. The four essential characteristics of advocacy were missing from these client descriptions and reflected negative nurse attributes, behaviors, and actions. Nurses who did not demonstrate characteristics of advocacy were perceived as incompetent in knowledge and performance or actions, and dehumanizing in relationships with clients and family. Incompetent in Knowledge and Performance/Actions

Nurses characterized as incompetent in knowledge and performance or actions displayed a lack of knowledge and/or experience or were knowledgeable but exercised poor judgement, provided incompetent or poor care, offered no help, met basic minimal physical needs technically but did not provide psychosocial care. They were unresponsive to 
client needs, took no corrective action on problem situations, interjected or forced their own viewpoints inappropriately, and displayed a lack of registered nurse leadership/supervision of care. As poor communicators, they failed to keep the client or family informed, had poor language skills, did not introduce or identify themselves as registered nurses, gave inappropriate or inadequate explanations, preparation and education, and failed to disclose desired appropriate information to the client. These characteristics are listed in Table 6. Thus, nurses who were described as being incompetent in knowledge and performance or actions did not demonstrate the essential advocacy characteristics of Competent Knower, competent Doer, and Communicator.

Unknowledgeable, inexperienced. Participants gave many descriptions of nurses whose lack of knowledge or inexperience in nursing practice resulted in emotional or physical discomfort.

Some were not 100 percent sure what to do in a given situation.

She didn't really look like she knew what she was doing hanging bottles, I was always afraid of her because I figured she might make a mistake.

She caused me a lot of discomfort. For 20 minutes she kept fooling around and finally went and got somebody else to put in the catheter. 
Table 6

Lack of Knowledge and Incompetent Performance/Actions:

Characteristics Converse to Advocacy

1. Unknowledgeable, inexperienced

2. Knew better but exercised poor judgement

3. Incompetent, poor care provided, no help offered

4. Met basic minimal physical needs technically but provided no psychosocial care

5. Unresponsive to client needs

6. Took no corrective action on problem situations

7. Interjected/forced own viewpoint inappropriately

8. Displayed a lack of registered nurse leadership/ supervision of care

9. Poor communication
a. Client/family uninformed
b. Poor language skills
c. Lack of introduction/identification as registered nurse
d. Inappropriate or inadequate explanation, preparation, education
e. Lack of disclosure of desired appropriate information to client

Knew better but exercised poor judgement. Participants also described nurses whom they perceived as knowledgeable 
and experienced but who used poor judgement in the care they provided. Participants stated that these nurses did not act as advocates, as indicated by the following examples:

A strong laxative was ordered by the doctor on call. She gave it without question and later said when I was in severe pain that she never gives that laxative because she thinks it is too strong.

She put the gloves from next door on my bed where I was laying and rolling around and then put them back up.

They never washed their hands.

They sometimes don't use wisdom, they tell the patient everything [that could possibly happen] and that causes some unnecessary fear.

Incompetent, poor care provided, no help offered.

There were many examples of nurses providing incompetent or

poor care and offering no help to the client.

They put the tray in front of a patient too weak to feed herself. They left it, came back and took it away. They didn't even try to feed the patient.

When I was in isolation, they didn't come into the room very often. At mealtimes the food was either cold or I never got a meal [because they didn't come into the room].

The sheets were rough, I got a rash on my back. It disturbed me that the sheets weren't removed for quite awhile.

Mother got rotten care, the nurses wouldn't come and help her.

The call bell [in ICU] didn't work when I needed them desperately, mother had a heart attack and I couldn't get a nurse.

She didn't take the pressure gauge off from around my arm and I had to call four or five times to get somebody to come and remove it. 
I had no help to get into bed. They said, "wait for the next shift."

My glasses were always where I couldn't reach them.

Met basic minimal physical needs technically but provided no psychosocial care. Several participants who had previously described emotional support provided by nurse advocates also described other nurses who may have met the client's basic physical needs but did not provide emotional support.

You're feeling physically rotten but you can also be mentally going crazy at the same time and there might not necessarily be someone to notice it.

In nurses' training nowadays, they have so much machines and bottles and so on, they really don't know how to relate to the person on the bed.

When you're sick there's not a lot to comfort you.

Emotional care was most lacking.

Most did not ask if there was anything I would like or that they can get for me.

Physical care was good but actual supportive measures, didn't see many of them.

Unresponsive to client needs. Participants described nurses as not responding or responding slowly to their needs.

They were slow answering the call bell.

I called many times, they said, "We'll be right in," and didn't come. Disgusting.

I was pretty patient, not too demanding, I knew they were all busy but when I wanted something like pain medication, I would get frustrated. I would call and it would take a long time to get the pain medication. 
Took no corrective action on problem situations. In describing negative experiences with nurses, several participants mentioned a lack of action on the part of a nurse to correct something, whereas they had described problem solving and taking corrective action as components of advocacy.

Bad things happened constantly but things didn't change.

I complained and it didn't go any further.

Interjected/forced own viewpoint inappropriately. Participants also described situations in which nurses failed to act as client advocates by interjecting their own viewpoints inappropriately.

The nurses took very authoritative roles and expressed their own views. The nurses were practicing medicine. If the patient wanted to deliver naturally and the nurse thought she should have an epidural, the nurse tried to talk the patient into the epidural.

The nurses tried to talk her [the birth mother] into keeping the baby [that she had prenatally arranged to adopt out to the participant]. They [the nurses] thought they were doing the best thing but they had no business interfering. They were putting their own personal viewpoints and making a decision that this girl had agonized over for a long time. They had only met her for an hour or two and the nurses decided she should keep it.

Displayed a lack of RN leadership/supervision of care. Participants also believe nurses are responsible for care that is and is not provided by others. Nurses who exhibited client advocacy as leaders and supervisors were described as taking responsibility for the care given by others, 
following through, and taking corrective action as necessary. on the other hand, if the care was consistently bad, clients perceived that the registered nurse did not provide the appropriate supervision and created an atmosphere of distrust.

The head nurse said, "the bedpan brigade is not on duty yet." Everything was, "next shift."

I never saw an $\mathrm{RN}$ at the horrible place.

At $5 \mathrm{a} . \mathrm{m}$. they pile the women in chairs, put them in the hall all day. They never move off the chair. The head nurse should see into that.

Can't tell the doctor what they [the aides] did to patients, they [the aides] stand right there, call you honey. Never told the head nurse on the nurse's aides what they done to other people, I might get picked on, I seen other people's lives made miserable.

Poor communication. Poor communication was described as almost the reverse of the essential advocacy characteristic of Communicator. The nurse failed to keep the client/family informed; exhibited poor language skills; did not introduce/identify self as a registered nurse; provided inappropriate or inadequate explanation, preparation, or education; and did not disclose desired and appropriate information to client. Participants described these poor communicators in great detail.

client/family uninformed

If someone had just stopped in and said, "We're running late, lunch is on it's way," that would have helped.

They spoke to the family only when the family initiated it. 
Poor language skilis

I had a problem understanding the nurse because of her foreign accent.

Lack of introduction/identification as registered nurse

Not sure which ones are RNs.

All wear name tags and colored shirts. Nobody wears a cap, it's hard to distinguish who is who.

She should have said, "Hello, I'm going to be your nurse today."

Inappropriate/inadequate explanation, preparation, education

I couldn't read the write-up on dismissal.

[At discharge] the doctor sat down and told me exactly what I was to do and not to do. The nurse put me in the wheelchair and pushed me out [no elaboration].

"Where were you, that's no way to be dressed to go out." Yelled at me, "you're going to get burned. I've seen people where their skin has peeled off their flesh."

They didn't say what they were looking for or why they were doing it.

They tell you everything, sometimes too much. They scared him by saying too much.

No one took the time to explain to me.

Didn't know what they were going to do. I was apprehensive over things I didn't need to be.

Lack of disclosure of information desired by client

Nearly everything [information] is kept from patients in hospitals.

I want to know more.

Doctors are busy, they may come and may not. It's a nightmare if you're not use to being in the hospital. Nurses should give information on how you're doing. 
Such descriptions of nurses not competent in knowledge or performance/actions and depicted as not being client advocates provides evidence that the advocacy characteristics of Competent Knower, Competent Doer, and Communicator are not demonstrated by all nurses. Dehumanizing

Moreover, nurses who did not exhibit the Humanizer essential characteristic of advocacy were described as depersonalizing, uncaring, isolating, ignoring, avoiding the client, displaying a poor attitudè, and being indifferent. They also had poor relationships with clients, families, and other health care providers by displaying no teamwork, appearing rushed and having no time for clients. They were perceived as rude, bothered by client needs, and not providing old fashioned supportive measures. The outcome of these dehumanizing relationships was that clients perceived nurses as not liking their jobs. Nurses who were dehumanizing did not demonstrate the essential advocacy characteristics of the Humanizer. Table 7 lists the characteristics associated with dehumanization as perceived in the negative experiences of clients. 
Table 7

Dehumanizing: Characteristics Converse to Advocacy

1. Depersonalizing

2. Uncaring

3. Patient isolated, ignored, avoided

4. Poor attitude, indifferent

5. Poor relationships with client/family/other health care providers, no teamwork

6. Rushed, no time for client, perceived as rude and being bothered by client needs

7. Lack of old fashioned supportive measures

Depersonalizing. Many participants vividly described negative experiences with nurses who did not treat them as human beings or with the dignity and respect displayed by nurses with the characteristics of advocacy.

She made me feel like a dog. They treat you like cattle.

She made me feel like a little kid.

It was depersonalization by not introducing herself to the patient and saying, "I'll be the one who will look after you today. If you need anything, ask for me."

They were trained and capable but they work like robots. They never once addressed the body in the bed.

I'm still here and there's so much going on and you just get lost, they forget about you and $I^{\prime} m$ a person.

They're burned out, just do what they have to do and see it as work; they're slow on doing their job. Don't treat the patient as a person, just a 
thing that you take care of; not taking that extra step. Why are you a nurse, why are you even here?

Uncaring. Participants, both as clients and as family members, viewed some nurses as uncaring. They described the effect uncaring nurses had on them.

Her angry tone of voice was frustrating to the patient and the family.

They were unkind to my mother. I would have liked her last days to have been a feeling that somebody cared for her.

I was angry that they didn't believe me [in pain], so angry $I$ was crying.

The majority of the nurses at the one hospital were totally hardened, totally could really care less.

Their philosophy was, "take care of yourself, we're not doing anything for you," feeling you got.

Caring about the person; how can you put carisig into it? If you haven't got it, you haven't got it.

Isolated, ignored, avoided the client. Several participants (especially the two who had been in isolation) described feeling isolated, ignored, and avoided by nurses.

When you're in isolation, you are literally in isolation, nobody comes around.

Unless you push the buzzer they don't even know you're in that room. No one comes in that room.

other participants also complained.

She only occasionally came at times not buzzed.

I called a couple of times, they always said somebody will be there, they never came. 
Poor attitude, indifferent. Likewise, several

participants commented on these negative attributes.

She was indifferent.

Her attitude was very poor like she was unhappy with work and would rather be someplace else.

Poor relationships with client/family/other health care

providers, no teamwork. Several participants described

negative relationships with nurses. As the client:

I never saw the same one twice. I missed the interpersonal relationship with a nurse.

Most of the nurses didn't even want to try [to relate to the patient], some might have tried but they didn't really click.

If I wanted to talk to somebody, I had to bring it up.

As a family member:

We worked hard to try to build a relationship with the nurses.

We felt like intruders, observers; we were not welcome to participate in the care.

We were never oriented to the facility and never folt, like we knew who was who or what was what.

Lack of teamwork and poor relationships with other health

care providers were described in the following terms:

I would have expected the nurse to be with the doctor when he comes in, while the doctor talks to you.

Doctors verbally abuse nurses.

Nurses with experience know that a warm pillow or something will help the patient and the doctor says no. Doctors don't take suggestions from nurses. 
Two participants described a negative effect of 12-hour

shifts on the nurse-client relationship.

They say 12-hour shifts are to give you more. I never got to know any of them hardly and they seemed to be cranky after their long shift.

With 12-hour shifts, you constantly have new nurses. You don't have the same development of a nurse-patient relationship. It's like breaking in a new nurse everyday.

Rushed, no time for client, perceived as rude and

bothered by client needs. All participants said that they thought nurses should come in more often, just to see how the client is doing and not necessarily to do something. Many nurses were perceived as not having any time for the client and acting rude and annoyed when anything was requested, contrasting with the positive experiences associated with nurses who displayed advocacy characteristics.

Just stated why they were there, do their job and run out of room.

Just didn't have the time.

I pushed the button, I hate doing that because I always feel like I'm inconveniencing them. "Ok, just hang on, I'm watching my TV program and you're bothering me" kind of feeling.

They act rude, annoyed, put upon. They sit and visit with each other, act annoyed if asked anything.

Lack of old fashioned supportive measures. Many participants mentioned backrubs specifically as an old fashioned supportive measure that is not provided anymore. Clients particularly praised the personalized feelings they 
had with those nurses who had offered backrubs, the same nurses they had described as exhibiting characteristics of advocacy.

No backrub, only the bed was changed, get washed and cleaned.

A backrub is worth a sleeping pill any day. There's too much focus on pills.

No old fashioned supportive measures, no offers to rub my back or neck.

outcome of dehumanization: perceived as not liking job.

Nurses who were dehumanizing did not demonstrate the

essential advocacy characteristic of the Humanizer. To

reiterate, the outcome of these actions and relationships

was that nurses were perceived as not liking their jobs and

not liking people.

Her attitude was very poor like she was unhappy

with work and would rather be someplace else.

She didn't like her job, she had no right being a nurse.

The negative experiences with registered nurses that

participants described depict these nurses as lacking in

knowledge and experience, demonstrating incompetency in

performance and actions, and dehumanizing in their

relationships with clients. These negative characteristics

manifested none of the essential characteristics of

advocacy. Advocacy was missing in these relationships and

experiences, as evidenced by client descriptions. 


\section{Client Reports of Self-sufficiency,}

\section{Self-reliance, Self-care}

Eight of the participants stressed, in some way, that they did not want to be dependent upon the nurses. Four of the participants described client self-reliance, selfsufficiency, or self-care.

I tried to do as much as I could for myself.

I didn't need much care. I didn't require any special care.

I like to be self-sufficient. If I can do it by myself, I would rather do it by myself. My care was pretty well structured; most of the things fairly routine. You don't bug them if you don't have to.

I didn't need any nurse's care. I was able to take care of myself from the very next day [after surgery]. They didn't do anything except regular duties; I didn't need anything, I did it myself.

Two described the overnight presence of significant others as security and comfort, mentioning that the significant other would get the nurse for whatever was needed, thus reducing reliance on the nurse.

Someone stayed overnight with him so he was never really alone. Especially if you're doped up, lying flat on your back, you can't always reach the basin or get help when you need it, or push the button. People are busy so you always feel if somebody else is around, you're safe.

Somebody stayed the first night. It was neat to know somebody was there, you could make a peep and they would take care of it.

Two participants described the relationship between education and client self-care and reliance.

It was something extra, she didn't have to, but she taught me how to use the trapeze and to get in 
and out of bed. Then I started living, I didn't have to wait for the nurse to put me into bed.

The nurse should tell you anything you can do to help yourself out, to speed recovery.

These additional findings related to self-care, selfreliance, and client independence were deemed important to the participants. 
CHAPTER FIVE

DISCUSSION OF THE FINDINGS

This chapter focuses on a discussion of the findings in four areas. The assumptions set forth in Chapter 1 are reviewed in light of the results of this investigation. Murphy, Gadow, Smith, and Kohnke's models of the nurseclient relationship are compared with the client's perspective of advocacy associated with the nurse-client relationship as found in this study. Thirdly, the differences between the clients' positive experiences with nurses who exhibited the characteristics of advocacy and the clients' negative experiences with nurses who lacked the characteristics of advocacy are examined. A discussion of advocacy as an integrated role within the whole of the nurse-client relationship concludes the chapter.

Assumptions Reviewed

The assumptions set forth in Chapter 1 were suspended during data collection, analysis, and reporting of the findings and are now reexamined and compared with the results of this investigation.

1. Advocacy is an integral part of the nurse-client relationship. 
Advocacy was not described in every nurse-client relationship. The essential characteristics extracted from client descriptions of their experiences with nurses support the premise that clients perceive advocacy as an integral part of the positive nurse-client relationship. on the other hand, advocacy was lacking in negative nurse-client relationships. Therefore, support for Assumption 1 is mixed.

2. Nursing considers advocacy a vital role for the professional nurse. Nurses assume the role of client advocate as part of their professional socialization. Literature supports that nursing considers advocacy a vital role for the professional nurse. Theoretical literature, the minimal investigations that have been undertaken, and the efforts put into the development of nurse-client relationship models confirm this. Yet no evidence from the findings indicated clients are aware of the importance nursing has placed on the advocate role. Even though clients did indicate the desire for nurses to be client advocates, still for some advocacy was not routinely expected.

From the client's perspective, the role of client advocate cannot be assumed to be part of nurses' professional socialization because all nurses did not exhibit the characteristics of advocacy. Clients described both positive experiences with nurses who demonstrated the 
essential characteristics of advocacy and negative experiences in which advocacy characteristics were missing. One might conclude incorrectly that some nurses are socialized to the role of client advocate while others are not: indeed, there might be distinctive reasons why nurses do not display advocacy behaviors. It might also be concluded, correctly or incorrectly, that some nurses do not want to be client advocates for unknown reasons.

3. Nurses advocate for human dignity and client rights to autonomy and for client participation in health care decision making.

Assumption 3 was only partially supported by the findings. Clients perceived that nurses advocated for human dignity, as evidenced by the essential characteristic, Humanizer. The findings, however, do not clearly suggest that nurses advocate for client rights to autonomy and participation in health care decision making. Clients did not perceive that they were offered many choices, and did not describe health care decision making in terms that would indicate that nurses advocated for client participation in decision making. Some clients described professionals as "the experts" who knew what was needed, and therefore accepted the professional's decision about what was the best course of action. 
4. The nurse may advocate for the client without the client's knowledge.

Assumption 4 was clearly supported by the data. Several clients specifically stated that nurses may have intervened on their behalf or solved a problem without making the client aware of their actions. Medication was also described as an amnesiac, compromising awareness of the nurse's actions.

5. Clients do not differentiate between advocacy and caring in the nurse-client relationship.

The data also supported Assumption 5. In fact, clients described in vivid detail experiences in which nurses were caring and taking action on their behalf in the same situation, sometimes delineated in the same sentence. To clients, caring was an integral component of advocacy. Nurses intervened or problem-solved because they cared about the client and respected the client as a human being. When asked directly about whether the nurse had been their advocate, some clients replied that it had not been necessary for the nurse to advocate for them. Yet they continued to describe the nurse in terms of the characteristics of advocacy, such as gatekeeper, problemsolver, information giver, and giver of caring, humanistic treatment.

Thus, assumptions 4 and 5 were supported by the data while assumptions 1,2 and 3 received only partial support. 
Assumptions 2 and 3 were made from a nurse's perspective about nurses and thus may have been only partially supported because clients did not observe or were unaware of the nurse's actions, making description impossible. Nurse-Client Relationship Models and The Client's Perspective

As previously presented, Cole Schonlau (1989) examined the similarities and disparities between Murphy (1979, 1983), Gadow (1979, 1980, 1983), Smith (1980), and Kohnke's (1980, 1982) models of the nurse-client relationship. The findings of this study revealed the client's perspective of advocacy associated with the nurse-client relationship. Also, clients did not differentiate advocacy as a separately identified role for nurses. Rather, they described the characteristics of advocacy associated with the nurse-client relationship as nurse attributes, behaviors, and actions integrated among all roles that encompass the professional nurse's practice. Because various nursing models of the nurse-client relationship related to clients' described integrated roles, elements from models in addition to advocacy are included in this discussion of the findings. The client's perspective provided varied support for these models. A comparison of the client's perspective and the nurse-client relationship models of Murphy, Gadow, Smith, and Kohnke demonstrated that the research findings support the conceptual relationships identified between the 
various proposed models (Cole Schonlau, 1989) as presented in Figure 1 (see page 27).

\section{Client Perceptions and Murphy's Models}

The "I-it" relationships described by Murphy (1979, 1983) as a consequence of the bureaucratic and physician advocacy models were described in clients' negative portraits of nurses. Clients who were not treated with respect and dignity as unique human beings saw nurses as uncaring and just doing a job they did not like. The findings only partially supported the physician advocacy model. Clients described instances of nurse-physician relationships and teamwork in which the nurse reinforced and perhaps acted to promote client trust in the physician ("the nurse told me my doctor was the best"). Clients, however, did not perceive that the nurse saw their relationship with the client as less important than the nurse-physician relationship.

The findings indicated that clients still see the physician as the leader and most knowledgeable, as in the bureaucratic model. Those who described discharge teaching by physicians did not indicate this as unusual or that they thought nurses were remiss for not having given the home care instructions. One client told the nurse who had given him information on the status of his infection that he "would not tell on her." Disclosing information was seen as primarily the physician's "bailiwick." This client wanted 
the nurse to give more information but feared she would get into trouble with the physician. In the bureaucratic model, clients are expected to know the limits of the nurse's role; however, many clients indicated a lack of knowledge about what to expect of the nurse.

client descriptions of advocacy associated with the nurse-client relationship supported Murphy's patient advocacy model. Clients described nurses as separate from physicians, not physician extenders, although wanting nurses to provide necessary information because physicians "are rarely there" and "the nurses have the information" and "should share the information" with the patient could be construed as physician extension rather than an essential characteristic of Communicator. The essential characteristic of advocacy, the Humanizer, was evident in client perceptions of being treated as unique human beings. As with the Competent Doer essential characteristic, clients perceived that their efforts to obtain care needs were facilitated even if the nurse, as client advocate, disagreed with the physician or institution.

\section{Client Perceptions and Gadow's Models of}

Paternalism and Existential Advocacy

Clients acknowledged that paternalism is appropriate and acceptable at times. They perceived that in many instances professionals were better qualified to define benefits and harm and, therefore, ethically were doing what 
was best to prevent harm. Some referred specifically to children, stating that "the nurse needs to interact and be a patient advocate with the pediatrician," or "they knew what was wrong with him and told me what they needed to do; there were no decisions for me to make." other clients described nurses and physicians as being "the experts" and having the "knowledge and experience" and "they knew what I needed." One client, however, vividly described the negative effects of paternalism, the use of force to promote the client's best interests and failure to respect the client's wishes. As a stroke victim, she was unable to communicate her fear and lack of knowledge about her diagnosis, treatments, and medicines. No one had explained anything to her. Nurses went into her room, forced medications down her throat, and nurse's aides abruptly turned her from side to side every two hours without ever speaking to her or forewarning her, and swore at her if she tried to resist. She also described an elderly woman who had been her roommate in a nursing home being carried to a tub room kicking and screaming that she did not want a bath. The findings in this study supported only one point in Gadow's (1980) existential advocacy model. The essential characteristic, Communicator, enhances client autonomy and fosters client independence and self-care by clarifying and providing information, and thereby increasing client knowledge. The results of this investigation indicated a 
lack of support for the other premises of Gadow's model in which the nurse participates and helps enhance client autonomy by examining available alternatives of action and assisting clients in clarifying their own beliefs, values, and goals. Gadow's hope is that an expression of the personal concept and meaning of health, illness, or death for that particular client is realized. From the descriptions offered by the participants in this study, it might be concluded that clients perceive that nurses do not have the time required to develop the relationship necessary to even begin such a personal endeavor. For example, clients said they had a different nurse everyday; such situations would make it difficult for the nurse to develop the personal rapport needed for existential advocacy. Equal involvement and disclosure of values by both client and nurse requires close understanding, which in turn requires time for the relationship to develop. Clients described a desire for self-sufficiency, self-reliance, and independence. They also desired family involvement in the nurse-client relationship. This might indicate that clients see this as an inappropriate role for the nurse. Hence, active involvement with the client to express personal reflections of health, illness, or death cannot be supported by the findings of this study. Clients described nurses as nonadvocates in two situations. Clients felt that active involvement in decision making was inappropriate, that the 
nurse was interjecting or forcing personal viewpoints upon the client.

\section{Client Perceptions and Kohnke's Advocacy Model and} Gadow's Consumerism/Patient Rights Model

The findings of this study suggested that clients experienced Kohnke's $(1980,1982)$ advocacy and Gadow's consumerism/patient rights models in some of their relationships with nurses. In both models the focus is on client autonomous decision making. Nurses provide the necessary information, withdraw, and allow clients to decide. Kohnke adds that, once clients make a decision, nurses support that decision, even if they believe it is not in the client's best interest. As one client said:

Once the patient has made up their mind what they are going to do, the nurse automatically says 'that's all I can do' or if the nurse has explained everything and the patient does not want to carry out the procedure, and that's it, the nurse can't act in behalf, but she is still being an advocate because she is supporting.

Kohnke and Gadow postulate that nurses do not assist clients with decision making; the findings of this study supported that premise as also being the client's perspective ("it is inappropriate for the nurse to be an advocate when she might be on one or the other side"). The viewpoints about decision making that clients described most were the aspects of information giving in the role of communicator and supporting in the role of Humanizer. 


\section{Clients Perceptions and Smith's Models}

Several clients described "mothering" as previously discussed under Gadow's paternalism model when, because of age or lack of knowledge, they had decreased ability to make choices. Likewise, in intensive care units they felt totally dependent on nurses for meeting their care needs. Surrogate mothering was also described as part of the essential characteristic of the Humanizer wherein nurses acted as cheerleaders and coaches and encouraged the client in eating, during treatments, and during labor.

Many elements of Smith's (1980) technician model are strongly supported by this study. Smith said that nurses had responsibility to act as advocates when clients perceived that protection was needed; this was expressed by the clients in this study. The aspects of Competent Doer, taking action as problem-solvers and intermediaries, and elements of the Humanizer, caring and intervening on behalf of the client's best interests, all serve to protect the client. Clients also acknowledged that nurses may take action on the client's behalf without the client knowing. The unspoken, unobserved advocacy of nurses finds support both in Smith's technician model and Murphy's patient advocacy model. In addition, clients described the application of knowledge and proficient performance in providing technically competent care as an essential 
characteristic of advocacy and as integrated within the whole of the nurse-client relationship.

The study findings failed to support Smith's contracted clinician model. Clients did not describe the nurse-client relationship as an agreement between the nurse and themselves. Also, there was little indication that clients felt they had control over the care they received and the role of the nurse to provide it. Clients expressed the desire for more frequent contact with the nurse and complained about some nurses who ignored them. In addition, findings did not reflect the client's perspective of the ethical aspects of refusing to participate in a nurse-client relationship based on values and beliefs; thus, there is further lack of support for Smith's clinician model.

A comparison of Murphy, Gadow, Smith, and Konnke's models of the nurse-client relationship and clients' perceptions of advocacy associated with the nurse-client relationship have provided a dialogue of support and contrasts. These models were found in both the experiences perceived as positive and experiences described as negative by study participants.

Negative Experiences and Positive Experiences:

\section{A Comparison}

clients described both positive experiences and negative experiences with nurses. In negative experiences nurses were perceived as portraying a lack of knowledge 
and/or experience, exhibiting poor judgement when they knew better, demonstrating incompetent performance and actions by providing poor care, offering no help when needed or only meeting minimal physical needs and ignoring psychosocial needs, taking no corrective action on problem situations, and displaying a lack of leadership or supervision of care. These nurses were also described as dehumanizing in their relationships with clients and family by ignoring and isolating the client, excluding the client and family from participation in care, depersonalizing and uncaring, not responding or slowly responding to client needs, interjecting or forcing their own viewpoint inappropriately, and communicating poorly with client, family, and others.

When comparing the descriptions of negative experiences with the positive experiences, it becomes apparent that what was missing in the negative experiences was client advocacy. In fact, by examining the description of nurses who did not demonstrate advocacy and the impact of those negatively perceived experiences, the positive impact of advocacy as integral to the nurse-client relationship and client satisfaction is highlighted. The findings of this investigation indicate that advocacy in the nurse-client relationship results in clients who perceive a positive interaction with the nurse. In contrast, negatively perceived experiences were those in which the essential characteristics of advocacy were not observed. These 
descriptions of nurses who demonstrated the characteristics of advocacy and nurses who did not reveal that advocacy is not an automatic role exhibited by all nurses in every situation or relationship. The extracted significant statements also indicate that, even if the characteristics of advocacy are not directly observed and described and not expected as routine, all participants desired client advocacy by nurses. Although clients may not have observed the nurse's actions on their behalf, they saw and described the consequences of those actions. Problems were corrected, needs were met, and good care was provided.

In concluding this section, a brief comment on inconsistent utilization of the advocate role is necessary. There may be many reasons why nurses do not utilize the advocate role more consistently or make their advocacy visible to clients. Nurses may choose to be "quiet" advocates. They may go about getting what they want for the client covertly and with great political finesse. Active, overt, aggressive advocacy invites risk. Clients acknowledged the risks of advocacy, indicating that active advocacy could jeopardize the nurse's position and relationship with professional colleagues. Nurses are socialized to maintain good relationships with other nurses and physicians. Courage is needed to fight the system and risk being ostracized or fired for client advocacy. 
Advocacy as an Integrated Role within the Nurse-Client Relationship

Although advocacy has been identified in the lived experiences of clients' relationships with registered nurses, clients did not indicate that advocacy was a distinct and separately identified role or that advocacy was more important or more essential to the nurse-client relationship than other roles. The findings suggest that advocacy as a role is integrated along with other nursing roles into the whole of the nurse-client relationship; perhaps there is such a strong interdependence between the roles that advocacy cannot be clearly differentiated as a separate entity.

Three previous studies hold significance for this discussion on advocacy as an integrated role within the nurse-client relationship and on nursing roles generally described as nurse attributes, behaviors, and actions. Attributes, behaviors, and actions reflected advocacy associated with the nurse-client relationship in this investigation. They were also reflected in the findings of previous studies on the nurse-patient relationship as experienced by the nurse (Smith, 1987), nursing behaviors satisfying to clients (Field, 1987) and the client's perspective of a caring nurse-client interaction (Reimen, 1983). 
The findings of this investigation support Smith's (1987) study in which nurses identified patient advocacy as one of the seven essential constituents of the nurse-patient relationship; the other six constituents (recognizing the patient as an holistic being deserving of respect and value, caring about the patient and his welfare, teaching the patient, interacting with the patient's family, taking care of physical needs, and recognizing the nurse's role and responsibilities toward patients) were described by participants in this investigation as components or minor characteristics of the essential characteristics of advocacy. This adds credence to the premise that advocacy is not a separate, distinct role but is integrated with other nursing roles into the whole of the nurse-client relationship.

The results of this investigation also provide support for Field's (1987) research findings that the nursing behaviors of being friendly, acting as parent advocate, intervening with doctor to express parental wishes, demonstrating knowledge, making parents feel at ease, listening, conveying respect, creating feelings of competence in care provided, and individualizing care were satisfying to clients. Again, differentiating behaviors specific to advocacy is difficult, especially when Field specified "intervening with doctors to express parents' wishes" as separate from "parent advocate." The clients of 
this investigation described all of these behaviors as elements of the essential characteristics of advocacy. The importance of the essential characteristics of competent Knower, Competent Doer, Humanizer, and Communicator in client advocacy are strengthened by the examination and comparison with Field's study.

Caring and presencing as portrayed by participants support Reimen's (1983) study that described the client's perspective of a caring nurse-client interaction. Reimen's participants depicted the nurse's existential presence as exhibited in the willingness of the nurse to give of herself by sitting down and really listening and responding to the unique concerns of the individual as a person of value. clients in this investigation described caring as an essential component of the Humanizer characteristic of advocacy. In reviewing the relationship that exists between caring and advocacy, it can be concluded that a nurse can be caring without being an advocate but a nurse cannot be an advocate without the component of caring.

It is postulated that the findings of this investigation and those of the studies by Smith (1987), Field (1987), and Reimen (1983) support attributes, behaviors, and actions as descriptive of various nursing roles. In addition, they support the premise that advocacy is part of the interdependent, integrated roles within the whole of the nurse-client relationship. 
CHAPTER SIX

IMPLICATIONS AND SUMMARY

The results of this study add credence to the limited nursing research on client advocacy. Implications and recommendations for further research in the nursing areas of clinical practice, education, and administration are discussed in this chapter. Closing the chapter is a summary of the salient points that highlighted this study and concluding recommendations.

\section{Clinical Practice}

The findings of this investigation have many implications for nurses in clinical practice. Nurse clinicians need to be aware of the impact their various behaviors have on relationships with clients and client expectations of nursing care behaviors. Clients described "good" nurses in their positive experiences as those who exhibited the essential characteristics of advocacy that were reflected as positive attributes, behaviors, and actions. They depicted "terrible" nursing as attributes, behaviors, and actions or lack of same in those experiences in which clients did not observe nurses demonstrating the characteristics of advocacy. Client advocacy is important to nursing, and although it is popular to claim that nurses are client advocates, nursing literature has reflected 
confusion about the nature of the nurse's role as client advocate (Bell, 1987; Curtin, 1988; Winslow, 1984). As discussed previously, the clients in this study did not perceive advocacy as an identifiably separate role of nurses but rather as integrated within the whole of the nurseclient relationship. Distinguishing between various nursing roles is an area that requires further inquiry from the client's perspective.

Although nurses claim to be client advocates, their utilization of the role was not consistently observed by clients. Is that because the client's memory or perceptions were faulty as a result of medication or because the nurses did not inform the clients of advocacy actions as described by some participants? or were the nurses actually not client advocates? Further research is needed on observations of nursing actions and comparisons of nurse and client perceptions of client advocacy role utilization by nurses. Several questions related to why nurses may not exhibit characteristics of advocacy are worthy of investigation. For example, is it due to lack of knowledge or experience in how to be an advocate, lack of desire to take that "extra step," or fear of risk-taking? Another area needing additional research is nurses' attitudes, perceptions, and degree of commitment to practice as they relate to advocacy in the nurse-client relationship. 
As previously presented, two participants described situations in which the nurse "interfered," "interjected her own personal viewpoints," and hence did not act as a client advocate. Droste (1978) theoretically postulated that client advocacy may be a legitimate role for nurses but it is also a privilege that the client needs to grant before the nurse assumes the role. Implicit or explicit consent is essential for a true partnership in the nurse-client relationship, and nurses must allow clients to educate them about their perceived needs (Droste, 1978). The study implies that nurses have been provided with some insight into client desire for advocacy in the nurse-client relationship and should not assume an advocacy role in isolation of the client just because they think it is appropriate. This study has only touched on the client's perspective of advocacy. Further research is needed on the various essential characteristics and in what situations clients desire or do not desire advocacy.

The repeated emphasis clients placed on nurse-family relationships in descriptions of their family's experiences with nurses or their own as family members of patients has strong implications for nurses. Family members may remember or be aware of the nurse's actions on the client's behalf even if clients are unaware. As one participant who had recently been both a patient and the mother of a patient phrased it: 
You notice things more when you're not the patient because when you're the patient you are on drugs so much.

The family's experiences with the nurse and inclusion on the team as part of an undifferentiated nurse-client/family relationship, have an important impact on advocacy observed and experienced in the nurse-client relationship, whether the client was the patient or family member responsible for the patient. A comparison study of clients and clients' families regarding advccacy role utilization by nurses is of interest.

Another implication for clinical practice is the degree to which clients desire to take part in health care decision making. Clients in the study who indicated that they did not have a lot of input into the treatment decisions for themselves or dependent family member noted that this was appropriate in their particular situations. One client did state that he had weighty input into the "no heroics" decision for his spouse. Although desire to participate in decision making varied, participants wanted more information and to be kept informed. This concurs with previous studies by Dennis (1987) and strull et al. (1984). The need for nurses to understand the degree of participation desired by clients was supported by Benner's (1984) study, in which she found that nurses recognized client needs for information and being kept informed. The implications of these studies and the current investigation are that nurses need to 
accurately assess individualized client needs in order to facilitate decision making control for those who desire it, and deemphasize participation for those who do not desire it.

Another implication for nurse clinicians is the relationship between the essential characteristics of advocacy and client independence and self-reliance. The nurse's knowledge and experience are required to assess client needs or lack of need for nursing assistance. Good rapport and communication with client, family, and others are necessary so that the nurse can assure that client needs are met, even if not directly provided by the nurse. In many instances emotional support and education by the nurse can facilitate and foster client self-reliance and selfcare. Participants expressed desire and appreciation for being given information (education) about what they could do for themselves to speed recovery. The nursing literature espouses advocacy as the holistic approach to a nurse-client relationship that emphasizes respect for individual dignity and autonomy, the right to self-determination, and thus facilitates self-care abilities (Hudson, 1988). Certainly, the results of this study confirm that client independence and self-care can be an outcome of advocacy.

Education

The results also have implications for both nurse educators and nurses as client educators. Clients described 
knowledge as essential for advocacy, and some specifically mentioned psychological education or counseling as part of nursing's curriculum. Healey (1983) wrote that the primary responsibility for preparation and encouragement of nurses in the role of patient advocate rests with the schools of nursing. Both technical competency and sensitivity to moral and legal obligations are necessary for educating the whole nurse. Jones (1982) agreed that nurses should be educated by the principles of advocacy and that a curriculum based on an advocacy theoretical framework should be developed. Hunter (1983) and Murphy (1979) both stressed that nurses should be better educated in the humanities because they provide the foundation of cultural and philosophical knowledge essential to better understand the uniqueness of each human being. The findings support these authors and stress the importance for nurse educators to be cognizant of advocacy throughout basic nursing education.

Some implications are shared by nurse educators and nurse administrators. Both need to promote the socialization process to autonomous professional practice and client advocacy. Education about the advocate role continues in practice, a responsibility which also must be assumed by hospital nursing inservice and administrators. Most clients in this study expressed that they desired advocacy from nurses but did not automatically expect it, concurring with winslow's (1984) statement that patients and 
families are often unprepared to accept the nurse as an advocate. Advocacy was not described as the principal function of nurses; it was described concurrently with other nursing functions. Findings indicated that clients may not be prepared to accept the nurse as an advocate because many clients are not very knowledgeable about the nurse's roles.

I don't know what to expect of a nurse on a oneto-one basis.

I'm not really sure what to expect from nurses except to be calming and reassuring and [pause] the comfort level of the patient and education when needed.

[home care assessment] put's an awful lot on the nurse, that should fall into somebody else's bailiwick, not the nurse's.

Nurse educators need to educate nurse clinicians on how to be client advocates and assist them in educating clients about what they can expect from nurses. All nurses, clinicians, educators, and administrators must demonstrate professional leadership in health care by educating the public about all the facets of nursing, including the role of client advocate.

\section{Administration}

Client expectations of nursing and satisfaction with nursing care behaviors, including the role of client advocate, have implications for nurse administrators. Concerns about costs in the currently financially troubled health care market and about inadequate numbers of professional nurses to provide for the increasing intensity 
of care during decreased lengths of stay in hospitals weigh heavily upon nurse executives. Additional client/consumer research focusing on nursing is recommended to shed insight into possible alternative care delivery systems. Study participants specifically mentioned several concerns that should be addxessed by nurse administrators. Streamlining documentation systems and delegating nonessential tasks to ancillary staff would allow the professional nurse more time with the client. The description of what was missing in the negative experiences raises concerns that client needs for contact with nurses are unmet. The humanistic aspects of care in guest relations programs need to be caddressed to a greater extent in nursing care. Nurses need to schedule time for such important details as going into the room just to see how the client is doing and if anything is needed or wanted. Nurse administrators need to look upon clients as allies. Client expectations and satisfaction should be considered and costs and benefits analyzed before potentially unnecessary strategic changes are implemented. Such an example might be adding personnel to payrolls to provide for assumed client needs, later determined to be unwanted.

Another area of concern to nurse administrators is nursing care delivery systems. Team nursing, total patient care, and primary nursing have all been methods of patient/client care delivery for decades. Various models of 
primary nursing and case management are now becoming popular trends. How these assorted nursing care delivery systems promote advocacy is important for administrative research. An investigational approach that compares utilization of client advocacy between units with different client care delivery systems is recommended.

Further research into client expectations of nursing, client advocacy by nurses, and degree of participation in health care decision making is needed before nurses make strong theoretical conclusions regarding the "consumer revolution." For example, the American Nurses' Association Cabinet on Nursing Research contends that by the year 2000 individuals will adopt a greater responsibility for their own health care, will demand higher quality service, and will insist upon the right to self-determination from all health professionals (American Nurses' Association, 1985b). Such a position requires empirical validation.

In this era of consumer revolution, nurses must investigate client perceptions of nursing care to increase awareness and provide a basis for improving consumer satisfaction (Gamotis, Dearmon, Doolittle, \& Price, 1988; Spitzer, 1988). Stellman (1988) postulated that consumers expect and need health care delivery by properly trained, accountable, caring practitioners; appropriate marketplace choices regarding levels of care and providers; adequate information to make informed choices; and active partnership 
in their own health care and governance. In addition, they are concerned about the availability and quality of bedside care in the hospital. Spitzer (1988) further stated that clients expect and nurses should provide information about patient rights, responsibilities, resources, and options regarding treatment. Investigations into these areas should be of prime consideration to nursing administration researchers. This study implies that further research related to client advocacy is needed in areas pertinent to nurse administrators, such as client expectations, client satisfaction, and client input into potential changes in nursing care delivery.

Results also indicated some clients believed that client advocacy involves risk-taking. Most expect nurses to act as client advocates and take specific and general client needs to their nurse administrators when unable to meet the needs for reasons such as disagreement with physician or lack of resources. The nurse administrator must demonstrate support for the clinician's role in client advocacy by being a nurse advocate and supporting the nurse in contentious situations. The needs are great and the time is right for nurse administrator involvement in research on advocacy and support for nurse clinicians as advocates.

\section{Summary}

This investigation sought to discover the client's perspective of advocacy in the nurse-client relationship by 
phenomenological methods. Four essential characteristics of advocacy emerged from the described lived experiences of the participants. They were labelled Competent knower, Competent Doer, Humanizer, and Communicator. The nurse displayed client advocacy when utilizing knowledge and experience, taking action on behalf of the client, and communicating in a manner reflecting respect and dignity for the client as a human being.

Potential research topics and implications arising from the findings of this study were identified for nurse clinicians, educators, and administrators. other studies that should be considered come from the description of advocacy associated with the nurse-client relationship from the perspective of these ten clients. All participants were caucasian with a wide age span; males and females were approximately equal in numbers, and all had experience with a nurse in a hospital. In addition, participants repeatedly described experiences as family members with nurses, and some participants described experiences in non-acute care settings. Are the essential characteristics identified here as the major components of advocacy in the nurse-client relationship the same characteristics that would emerge in clients from another area of the country, of a different ethnic group, in an all ambulatory setting, or in a children's hospital? Studies with different participants 
are important to determine if the findings are generalizable to a wider population.

The suggestions offered in this chapter do not begin to touch the research potential inherent in the description of advocacy associated with the nurse-client relationship. For this potential to be realized, this description needs to be shared so that it can be confirmed and corroborated by researchers both in nursing and in other disciplines.

In summary, clients are the central focus of nursing's practice, and as clinical practitioners, educators, and administrators, nurses advocate for clients' needs. Understanding clients' perceptions of the nurse-client relationship and advocacy in particular is thus imperative. Further research into client advocacy, client expectations, and client satisfaction with nursing care is essential, because only when the client's perspective has been exposed and understood can nursing address strategies to meet client expectations of nursing practice. This study only begins to address the need for client input. 
References

Allen, S. A. S. (1981). An anthropological study of nursepatient interactions. Dissertation Abstracts International, 42, 563B. (University Microfilms No. 81-16152)

American Nurses' Association. (1980). Nursing: A social policy statement. Kansas City, MO: Author.

American Nurses' Association. (1985a). Code for nurses with interpretative statements. Kansas City, MO: Author. American Nurses' Association. (1985b). Directions for nursing research: Toward the twenty-first century. Kansas City, MO: Author.

Annas, G. J., \& Healey, J. (1974). The patient rights advocate. Journal of Nursing Administration, 4, 2531.

Aroskar, M. A. (1980). The fractured nurse: The public stereotype of nursing and the nurse. In S. F. Spicker \& S. Gadow (Eds.), Nursing: Images and ideals (pp. 1833). New York: Springer.

Ashford, J. B., Macht, M. W., \& Mylym, M. (1987). Advocacy by social workers in the public defender's office. Social Work, $\underline{32}(3), 199-203$. Aydelotte, M. K. (1978). The patient's bill of rights Implications for the health care system. In Consumerism and health care (Pub. No. 52-1727, pp. 3539). New York: National League for Nursing. 
Bader, M. M. M. (1988). Nursing care behaviors that predict patient satisfaction. Journal of Nursing Quality Assurance, $2(3), 11-17$.

Baer, E. D., \& Lowery, B. J. (1987). Patient and situational factors that affect nursing students' like or dislike of caring for patients. Nursing Research, 36(5), 298-303.

Barrow, S. R. (1988). My sister isn't the only one who won't forget her nurses. RN, 51(3), 23-24.

Beauchamp, T. L., \& Childress, J. F. (1983). Principles of biomedical ethics (2nd ed.). New York: Oxford University Press.

Bell, B. R. (1987). Client advocacy in nursing: A contemporary perspective. Dissertation Abstracts International, 49, 0073B. (University Microfilms No. 88-03966)

Bendor, S. J. (1987). The clinical challenge of hospitalbased social work practice. Social Work in Health Care, 13(2), 25-34.

Benner, P. (1984). From novice to expert: Excellence and power in clinical nursing practice. Menlo Park, CA: Addison-Wesley.

Blazyk, S., Crawford, C., \& Wimberley, E. T. (1987). The ombudsman and the case manager. Social Work, 32(5), 451-453. 
Bogdan, R., \& Taylor, S. J. (1975). Introduction to gualitative research methods: A phenomenological approach to the social sciences. New York: Wiley. California Board of Registered Nursing. (1985). Competent Nurse Criteria. Business and professions code, title 16, article 4, section 1443.5. Sacramento, CA: Author.

Carney, B. (1987) - Bone marrow transplantation: Nurses' and physicians' perceptions of informed consent. Cancer Nursing, 10(5), 252-259.

Christy, T. E. (1973). New privileges...new challenges...new responsibilities. Nursing, $3(11), 8$, 11.

Cohen, D. L., McCullough, L. B., Kessel, R. W. I., Apostolides, A. Y., Heiderich, K. J., \& Alden, E. R. (1988). A national survey concerning the ethical aspects of informed consent and role of medical students. Journal of Medical Education, $63(11), 821-$ 829.

Colaizzi, P. F. (1978). Psychological research as the phenomenologist views it. In R. S. Valle \& M. King (Eds.), Existential-phenomenological alternatives for psychology (pp. 48-71). New York: Oxford University. Cole Schonlau, V. L. (1989, January). Patient advocacy as a role for the nurse in the nurse-patient relationship. Paper presented to the nursing faculty at the 
University of San Diego during doctoral candidacy oral examinations, San Diego, CA.

Cooper, M. C. (1988). Covenantal relationships: Grounding for the nursing ethic. Advances in Nursing science, $10(4), 48-59$.

Corcoran, S. (1988). Toward operationalizing an advocacy role. Journal of Professional Nursing, 4(4), 242-247. Cronin, S. N., \& Harrison, B. (1988). Importance of nurse caring behaviors as perceived by patients after myocardial infarction. Heart \& Lung, 17(4), 374-380. Curtin, L. (1979). The nurse as advocate: A philosophical foundation for nursing. Advances in Nursing Science, $1(3), 1-10$.

Curtin, L. (1982). The nurse-patient relationship: Foundation, purposes, responsibilities, and rights. In L. Curtin \& M. J. Flaherty (Eds.), Nursing ethics: Theories and pragmatics (pp. 79-86). Bowie, MD: Prentice-Hall.

Curtin, L. (1988). Ethics in nursing practice. Nursing Management, $19(5), 7-9$.

Davis, A. J. (1978). The phenomenological approach in nursing research. In N. Chaska (Ed.), The nursing profession: Views through the mist (pp. 186-196). New York: McGraw-Hill.

Davis, A. J., \& Jameton, A. (1987). Nursing and medical student attitudes toward nursing disclosure of 
information to patients. A pilot study. Journal of Advanced Nursing, 12(6), 691-698.

Dennis, K. E. (1987). Dimensions of client control. Nursing Research, 36(3)，151-156.

Dictionary of philosophy and psychology (1960) (vol. 1). Gloucester, MA: Peter Smith.

Donahue, M. P. (1978). The nurse a patient advocate? Nursing Forum, 17(2), 143-151.

Drew, N. (1986). Exclusion and confirmation: A phenomenology of patients' experiences with caregivers. Image, 18(2), 39-43.

Droste, M. A. (1978). The consumer and the health care profession - Contented marriage or shotgun wedding? In Consumerism and health care (Pub. No. 52-1727, pp. 35-39). New York: National League for Nursing. Epstein, I. (1981). Advocates on advocacy: An exploratory study. Social Work Research and Abstracts, 17(2), 512 .

Eraker, S. A., \& Politser, P. (1982). How decisions are reached: Physician and patient. Annals of Internal Medicine, 97, 262-268.

Fay, P. (1978). In support of patient advocacy as a nursing role. Nursing Outlook, 26(4), 252-253.

Field, P. A. (1987). Maternity nurses: How parents see us. International Journal of Nursing Studies, 24(3), 191199. 
Field, P. A., \& Morse, J. M. (1985). Nursing research: The application of qualitative approaches. Rockville, MD: Aspen.

Flaherty, M. J. (1982). The nurse-physician relationship. In L. Curtin \& M. J. Flaherty (Eds.), Nursing ethics: Theories and pragmatics (pp. 137-151). Bowie, MD: Prentice-Hall.

Flaskerund, J., Halloran, E., Janken, J., Lund, M., \& Zetterland, J. (1979). Avoidance and distancing: A descriptive view of nursing. Nursing Forum, 15, 158174.

Fraser, V. (1987). Physician and ombudsman in long term care. Colorado Medicine, 84(12), 271-272. Gadow, S. (1979). Advocacy nursing and new meanings of dying. Nursing Clinics of North America, 14(1), 8191 .

Gadow, S. (1980). Existential advocacy: Philosophical foundation of nursing. In S. F. Spicker \& S. Gadow (Ẽas.), Nursing: Images and ideals (pp. 79-101). New York: Springer. Gadow, S. (1983). Basis for nursing ethics: Paternalism, consumerism, or advocacy? Hospital progress, 64.(10), $62-67,78$.

Gamotis, P. B., Dearmon, V. C., Doolittle, N. O., \& Price, S. C. (1988). Inpatient vs outpatient satisfaction. AORN Journal, $47(6), 1421-1422,1424-1425$. 
Giorgi, A. (1985). Sketch of a psychological phenomenological method. In A. Giorgi (Ed.), Phenomenology and psychological research (pp. 8-22). Pittsburgh, PA: Duquesne University.

Healey, J. M. (1983). Patient rights and nursing. In C. P. Murphy \& H. Hunter (Eds.), Ethical problems in the nurse-patient relationship (pp. 113-121). Boston: Allyn \& Bacon.

Hotchkiss, W. S. (1987). Doctor as patient advocate. Journal of the American Medical Association, 258(7), 947-948.

Hudson, R. E. (1988). Whole or parts: A theological perspective on "person." Australian Journal of Advanced Nursing, $\underline{6}(1), 12-20$.

Hunter, H. (1983). Nursing: A humane profession. In C. P. Murphy \& H. Hunter (Eds.), Ethical problems in the nurse-patient relationship (pp. 27-38). Boston: Allyn \& Bacon.

Husserl, E. (1965). Phenomenology and the crisis of philosophy (Q. Lauer, Trans.). New York: Harper \& Row.

Husserl, E. (1970). The crisis of European sciences and transcendental phenomenology (D. Carr, Trans.). Evanston, IL: Northwestern University. 
Jones, E. W. (1982). Advocacy: A tool for radical nursing curriculum planners. Journal of Nursing Education, $21(1), 40-45$.

Kelly, L. Y. (1976). The patient's right to know. Nursing outlook, 24(1), 26-32.

Kim, H. S. (1987). Collaborative decision making with clients. In K. J. Hannah, M. Reimer, W. C. Mills, \& S. Letourneau (Eds.), clinical judgement and decision making: The future with nursing diagnosis (pp. 58-62). New York: Wiley.

King, I. (1971). Towards a theory for nursing. New York: wiley.

Klocke, F. J. (1988). Past president's page: Physicians as advocates in the 1980 s and 1990s. Journal of the American College of Cardiology, 12(1), 286-287.

Kohnke, M. F. (1980). The nurse as advocate. American Journal of Nursing, 80(11), 2038-2040.

Kohnke, M. F. (1982). Advocacy: Risk and reality. St. Louis: C. V. Mosby.

Kosik, S. H. (1972). Patient advocacy or fighting the system. American Journal of Nursing, 72(4), 694-698. Lanara, V. A. (1976). Philosophy of nursing and current nursing problems. International Nursing Review, $\underline{23}(2), 48-54$.

Landon, D. D. (1985). Clients, colleagues, and community: The shaping of zealous advocacy in country law 
practice. American Bar Foundation Research Journal, pp. $81-111$.

Lindes, C. (1988). The physician's role--Advocate or gatekeeper? Onio Medicine, $84(5), 343$.

Lofland, J., \& Lofland, L. H. (1984). Analyzing social settings: A quide to qualitative observation and analysis (2nd ed.). Belmont, CA: Wadsworth. Lumpp, S. F. (1979). The role of the nurse in the bioethical decision making process. Nursing Clinics of North America, 14(1), 13-21.

Lurie, A. (1982). The social work advocacy role in discharge planning. Social Work in Health Care, $\underline{8}(2)$, 75-85.

Magilvy, J. K., Brown, N. J., \& Dydyn, J. (1988). The experience of home health care: Perceptions of older adults. Public Health Nursing, $5(3), 140-145$. Mappes, T. A., \& Zembaty, J. S. (1986). Biomedical ethics (2nd ed.). New York: McGraw-Hill. Marsden, C. (1988). Caregiver fidelity in a pediatric bone marrow transplant unit. Heart \& Lung, 17(6), 617-625. Marshall, C., \& Rossman, G. B. (1989). Designing qualitative research. Newbury Park, CA: Sage. Merleau-Ponty, M. (1964). The primacy of perception (J. M. Edie, Ed. \& Trans.; W. Cobb, A. B. Dallery, C. Dallery, J. Flodstrom, N. Metzel, \& J. Wild, Trans.). Evanston, IL: Northwestern University. 
Miles, S. H. (1988). Paternalism, family duties and my Aunt Maude. Journal of the American Medical Association, $259(17), 2582-2583$.

Milner, N. (1986). The symbols and meanings of advocacy. International Journal of Law and Psychiatry, 8⑴, 117.

Munhall, P. L., \& Oiler, C. J. (1986). Nursing research: A qualitative perspective. Norwalk, CT: AppletonCentury-crofts.

Murphy, C. P. (1979). Ethical aspects of decision making in nursing. Political, social, and educational forces on nursing: Impact of social forces (Pub. No. 15-1774, pp. 17-25). New York: National League for Nursing. Murphy, C. P. (1983). Models of the nurse-patient relationship. In. C. P. Murphy \& H. Hunter (Eds.), Ethical problems in the nurse-patient relationship (pp. 9-24). Boston: Allyn \& Bacon. National League for Nursing. (1978). Nursing's role in patients' rights. Consumerism and health care (Pub. No. 52-1727, pp. 47-50). New York: Author. Nelson, M. L. (1988). Advocacy in nursing. Nursing outlook, 36(3), 136-141. Novello, D. J. (1978). The consumer's role in health care. Consumerism and health care (Pub. No. 52-1727, pp. 16). New York: National League for Nursing. 
Oiler, C. J. (1986). Qualitative methods: Phenomenology. In P. Moccia (Ed.), New approaches to theory development (Pub. No. 15-1992, pp. 75-103). New York: National League for Nursing. Oiler Boyd, C. (1989). Clarifying the issues. Nursing Science Quarterly, 2(1), 16-19.

Omery, A. (1983). Phenomenology: A method for nursing research. Advances in Nursing Science, $\underline{5}(2), 49-63$. Oxford English Dictionary (1933) (vol. 1). Oxford, England: Clarendon Press. payton, R. J. (1979). Information control and autonomy: Does the nurse have a role: Nursing Clinics of North America, 14 (1), 23-33.

Pearlman, M. H., \& Edwards, M. G. (1982). Enabling in the eighties: The client advocacy group. Social Casework, $\underline{63}(9), 532-539$.

Pluckhan, M. L. (1970). The nurse-patient relationship in the home setting. Dissertation Abstracts International, 31, 4159B. (University Microfilms No. $71-2457)$

Polit, D. F., \& Hungler, B. P. (1989). Essentials of nursing research (2nd ed.). Philadelphia: Lippincott. Quinn, N., \& Somers, A. R. (1974). The patient's bill of rights: A significant aspect of the consumer revolution. Nursing outlook, 22(4), 240-244. 
Reimen, D. J. (1986). The essential structure of a caring interaction: Doing phenomenology. In P. L. Munhall \& C. J. Oiler (Eds.), Nursing research: A qualitative perspective (pp. 85-108). Norwalk, CT: AppletonCentury-Crofts.

Rubenstein, L. S. (1986). Treatment of the mentally ill: Legal advocacy enters the second generation. American Journal of Psychiatry, 143(10), 1264-1269.

Salsberry, P. J. (1989). Phenomenological research in nursing: Fundamental questions. Nursing science Quarterly, 2(1), 9-13.

Sandelowski, M. (1986). The problem of rigor in qualitative research. Advances in Nursing Science, 8 (3), 27-37. Sandroff, R. (1981). Protecting the MD...or the patient? Nursing's unequivocal answer. $\underline{\mathrm{RN}}, \underline{44}(2), 28-33$. Schatzman, L., \& Strauss, A. L. (1973). Field research. Englewood Cliffs, NJ: Prentice-Hall. Schindler, D. (1982). Human rights and humanitarian law. The American University Law Review, 31, 935-943. Smith, E. (1987). A phenomenological investigation of the nurse-patient relationship. Unpublished master's thesis, University of California, Los Angeles, CA. Smith, M. C. (1989). Facts about phenomenology in nursing. Nursing Science Quarterly, 2(1), 13-16. Smith, S. (1980). Three models of the nurse-patient relationship. In S. F. Spicker \& S. Gadow (Eds.), 
Nursing: Images and ideals (pp. 176-188). New York: springer.

Sparrow, M. W. (1978). Consumerism: Its impact on America's health professionals. In Consumerism and health care (Pub. No. 52-1727, pp. 7-18). New York: National League for Nursing.

Spitzer, R. B. (1988) - Meeting consumer expectations. Nursing Administration Quarterly, 12(3), 31-39. Stewart, D., \& Mickunas, A. (1974). Exploring phenomenology. Chicago: American Library Association. Stellmann, C. B. (1988). Nursing: A consumer perspective. Nursing Administration Quarterly, 12(3), 12-16. Strull, W. M., Lo, B., \& Charles, G. (1984). Do patients want to participate in medical decision making: Journal of the American Medical Association, 252(21), 2990-2994 .

Sucharitkul, S. (1987). A multi-dimensional concept of human rights in international law. Notre Dame Law Review, 62, 305-317.

Sundeen, S. J., stuart, G. W., Rankin, E. A. D., \& Cohen, S. A. (1989). Nurse-client interaction (4th ed.). St. Louis: C. V. Mosby. Taylor, S. J., \& Bogdan, R. (1984). Introduction to qualitative research: The search for meanings (2nd ed.). New York: John Wiley \& Sons. 
Tilley, J. D., Gregor, F. M., \& Thiessen, V. (1987). The nurse's role in patient education: Incongruent perceptions among nurses and patients. Journal of Advanced Nursing, 12(3), 291-301.

Thompson, J. E. (1982). Conflicting loyalties of nurses working in bureaucratic settings. Professionalism and the empowerment of nursing: Papers presented at the 53rd convention (pp. 27-37). Kansas City, MO: American Nurses' Association. Thompson, J. E., \& Thompson, H. O. (1985). Bioethical decision making for nurses. Norwalk, CT: AppletonCentury-Crofts.

Valle, R. S., \& King, M. (1978). An introduction to existential-phenomenological thought in psychology. In R. S. Valle \& M. King (Eds.), Existentialphenomenological alternatives for psychology (pp. 317). New York: oxford University. Walsh, M. E. (1978). Nursing's responsibility for patients' rights. In consumerism and health care (Pub. No. 521727, pp. 19-27). New York: National League for Nursing. Webster's ninth new collegiate dictionary (1986). Springfield, MA: Merriam-Webster. willets, R. (1980). Advocacy and the mentally ill. Social Work, 25(5), 372-377. 
Winslow, G. R. (1984). From loyalty to advocacy: A new metaphor for nursing. Hastings Center Report, 14(3), $32-40$.

Wolf, S. M. (1988). Conflict between doctor and patient. Law, Medicine, and Health Care, 16(3-4), 197-203.

Yarling, R. R., \& MC Elmurry, B. J. (1986). The moral foundation of nursing. Advances in Nursing Science, $\underline{8}(2), 63-73$.

Zaner, R. M. (1970). The way of phenomenology. New York: Pegasus. 
Appendix A

\footnotetext{
Reproduced with permission of the copyright owner. Further reproduction prohibited without permission.
} 
Appendix A

Letter to Community Health Care Professionals Regarding

Study and Request for Referral of Potential Participants

Victoria L. Cole Schonlau

28127 Ridgepoint court

Rancho Palos Verdes, CA 90274

(213) 544-7252

(Date)

(Name)

(Title)

(Agency)

Dear () :

This letter is in follow up to our verbal discussion of the study pertaining to my doctoral dissertation. The purpose of my study is to describe the essential characteristics of the nurse-client relationship from the perspective of the client.

Nurses consider patients/clients to be the central focus of our practice. The nurse-patient/client relationship is regarded as the therapeutic interaction between nurse and client/client's significant others during the time period that the client is being provided nursing service.

The clients' perspective of the nurse-client relationship is of primary concern to nursing. The proposed study would increase knowledge of client perceived quality of care and satisfaction by providing insight into client experiences with nurses and nursing behaviors. Nurses need to know what nursing behaviors clients find desirable and what nursing roles are meaningful to clients in the nurse-client relationship.

I wish to interview clients who have had the experience of an interaction with a registered nurse and with their permission, tape the interviews for later transcription so that I may listen more intently during the interview and not write extensively. Interviews will be conducted at a time and place mutually agreed upon by the participant and myself. The estimated length of the interviews is expected to be between one to two hours. Anonymity will be protected throughout the entire project and participants may withdraw at any time if they feel uncomfortable. 
The criteria for inclusion in the study are that volunteer participants be willing and able to verbalize past and present experiences and feelings, be committed to seeing the project through to the end, be at least 18 years old, speak English, and have had an experience with a registered nurse within the past six months.

Would you please share this letter with your clients and have any clients who express an interest and willingness to participate sign their names, addresses and phone numbers on the enclosed form. Enclosed, you will find for your convenience a self-addressed, stamped envelope to return the volunteer listing. Upon receipt of the volunteer form, I will be contacting the individual volunteers to set up appointments for the interviews. If clients prefer to contact me directly, please give them a copy of this letter so that they have my name and phone number.

This is a wonderful opportunity for clients, as consumers of nursing services to discuss and describe their experiences with nurses, what they like and what they feel is missing. I am very excited about the opportunity to learn from them. I very much appreciate your sharing this letter with them.

Please feel free to make as many copies of this letter and volunteer participant list as you would like. I would be delighted to answer any questions you or potential

participants may have. Please call me at (213) 544-7252.

Thank you for your attention in this matter.

Sincerely,

Victoria L. Cole Schonlau

Dissertation Chair:

Dr. Janet Harrison

Associate Professor, Philip Y. Hahn School of Nursing Doctorate of Nursing Science Program

University of San Diego

Alcala Park

San Diego, CA 92110

(619) 260-4688 
151

Appendix B

Reproduced with permission of the copyright owner. Further reproduction prohibited without permission. 


\author{
UNIVERSITY OF SAN DIEGO \\ Consent to Participate in a Research study
}

I give permission for victoria cole schonlau, a doctoral candidate at the School of Nuraing, University of San Diego, to interview me regarding my experiences with nurses. I understand that the data will provide needed information to enhance the relationship between nurses and patients and to increase nursing knowledge about which nursing care behaviors are desired by patients and subsequently to increase patient satisfaction with nursing care.

I understand that my participation is completely voluntary, and I may withdraw from the study at any time without prejudice. I will receive no compensation, financial or otherwise, and there are no physical, social, or psychological benefits or risks involved.

There was the opportunity to ask questions about the study prior to signing this form and my questions were answered to my satisfaction. I can call victoria Schonlau at any time at (213) 544-7252.

I understand the interview will last approximately one to two hours and will be tape recorded. Additional interview time may be needed.

I understand that the information collected will remain confidential. I further understand that to preserve my anonymity only group data will be used in any publication of this study.

There is no agreement between myself and the researcher, written or verbal, beyond that expressed on this consent form.

$I$, the undersigned, understand the above explanations and, on that basis, I give consent to my voluntary participation in this research.

Signature of Subject

Locarion (e.g. Los Angeles, CA)

Signature of Researcher

Date

Dissertation Chair:

Dr. Janet Harrison

Associate Professor, Philip Y. Hahn School of Nursing

Doctorate of Nursing Science Program

University of San Diego

Alcala Park, San Diego, CA 92110

(619) 260-4688 